ARTICLE

DOI: $10.1038 /$ s41467-018-07201-1

\title{
A hPSC-based platform to discover gene-environment interactions that impact human $\beta$-cell and dopamine neuron survival
}

Ting Zhou', Tae Wan Kim²,3, Chi Nok Chong', Lei Tan,4, Sadaf Amin1, Zohreh Sadat Badieyan, Suranjit Mukherjee ${ }^{1}$, Zaniar Ghazizadeh ${ }^{1}$, Hui Zeng ${ }^{1}$, Min Guo ${ }^{1}$, Miguel Crespo ${ }^{1}$, Tuo Zhang (1) ${ }^{5}$, Reyn Kenyon ${ }^{1}$ Christopher L. Robinson ${ }^{1}$, Effie Apostolou ${ }^{6}$, Hui Wang ${ }^{4}$, Jenny Zhaoying Xiang ${ }^{5}$, Todd Evans ${ }^{1}$, Lorenz Studer ${ }^{2,3} \&$ Shuibing Chen ${ }^{1,7}$

Common disorders, including diabetes and Parkinson's disease, are caused by a combination of environmental factors and genetic susceptibility. However, defining the mechanisms underlying gene-environment interactions has been challenging due to the lack of a suitable experimental platform. Using pancreatic $\beta$-like cells derived from human pluripotent stem cells (hPSCs), we discovered that a commonly used pesticide, propargite, induces pancreatic $\beta$-cell death, a pathological hallmark of diabetes. Screening a panel of diverse hPSC-derived cell types we extended this observation to a similar susceptibility in midbrain dopamine neurons, a cell type affected in Parkinson's disease. We assessed gene-environment interactions using isogenic hPSC lines for genetic variants associated with diabetes and Parkinson's disease. We found GSTT1-/- pancreatic $\beta$-like cells and dopamine neurons were both hypersensitive to propargite-induced cell death. Our study identifies an environmental chemical that contributes to human $\beta$-cell and dopamine neuron loss and validates a novel hPSC-based platform for determining gene-environment interactions.

\footnotetext{
${ }^{1}$ Department of Surgery, Weill Cornell Medical College, 1300 York Ave, New York 10065 NY, USA. ${ }^{2}$ The Center for Stem Cell Biology, Sloan-Kettering Institute for Cancer Research, New York, NY 10065, USA. ${ }^{3}$ Developmental Biology Program, Sloan-Kettering Institute for Cancer Research, New York, NY 10065, USA. ${ }^{4}$ School of Public health, Shanghai Jiao Tong University, School of Medicine, Shanghai 200000, China. ${ }^{5}$ Genomic Resource Core Facility, Weill Cornell Medical College, 1300 York Ave, New York 10065 NY, USA. ${ }^{6}$ Department of Medicine, Weill Cornell Medical College, 1300 York Ave, New York 10065 NY, USA. ${ }^{7}$ Department of Biochemistry, Weill Cornell Medical College, 1300 York Ave, New York 10065 NY, USA. These authors contributed equally: Ting Zhou, Tae Wan Kim. Correspondence and requests for materials should be addressed to L.S. (email: studerl@mskcc.org) or to S.C. (email: shc2034@med.cornell.edu)
} 
D iabetes is a polygenetic disease affected by both genetic and environmental factors, with the pathological hallmark of pancreatic $\beta$-cell death or failure. Genome-wide association studies have identified more than 80 candidate gene variants associated with diabetes ${ }^{1-5}$. A large number of these diabetes-associated genes are expressed in pancreatic $\beta$-cells ${ }^{6}$, which highlights the importance of pancreatic $\beta$-cells themselves in the pathogenesis of diabetes. However, $<10 \%$ of genetically susceptible individuals progress to type 1 diabetes $^{7}$, and gene variants explain a very small proportion of type 2 diabetes risk ${ }^{8}$, which emphasizes the contribution of environmental factors in triggering or accelerating pancreatic $\beta$-cell loss. A recent report on U.S. synthetic chemical production suggested a causative role for synthetic chemicals in the pathogenesis of diabetes ${ }^{9}$. Indeed, several epidemiological studies linked environmental chemical toxins, such as polychlorinated biphenyls ${ }^{10,11}$, bisphenol $\mathrm{A}^{12-15}$, and heavy metals including arsenic ${ }^{16}$, to an increased prevalence of diabetes. However, no systematic investigations on the role of environmental chemicals in human pancreatic $\beta$-cell death have been reported, due to the lack of an appropriate, robust, timeefficient and cost-efficient screening platform. In addition, the response to environmental toxins may vary based on genetic background. Thus, how environmental factors interact with candidate genes and contribute to disease progression remains largely unknown.

Understanding gene-environment interactions is critical to decode disease progression and develop novel precision therapies in diabetes as well as in neurodegenerative disorders such as Parkinson's disease (PD). Most of the current gene-environment interactions are examined via human population studies, which are complicated by the diverse genetic backgrounds of the subjects and the myriad of environmental conditions to which those individuals are exposed. Such studies typically require extremely large sample sizes to identify the interaction of genetic and environmental factors. A recent study using isogenic induced pluripotent stem cells (iPSCs) from PD patients provided a preview for the potential of using human embryonic stem cells (hESCs) and iPSCs to study the gene-environment interactions in disease pathogenesis ${ }^{17}$. Here, we combined directed differentiation of hESCs with gene-editing techniques to derive isogenic human pancreatic $\beta$-like cells carrying diabetes-associated variants, and used these to study gene-environment interactions relevant to $\beta$-cell survival. Notably, we found that these interactions similarly apply to midbrain dopamine neurons in the context of Parkinson's disease. The results suggest previously unappreciated similarities in the susceptibility of pancreatic $\beta$-cells and midbrain dopamine neurons to certain environmental toxins, and indicate broad applicability of our hPSC-based platform.

\section{Results}

A HTS to identify chemicals that target human $\beta$-cells. We first sought to systematically explore the effects of environmental chemicals on human pancreatic $\beta$-cell survival using hESCderived insulin-expressing (INS ${ }^{+}$) $\beta$-like cells. To perform the chemical screen, H1 hESCs were differentiated toward INS ${ }^{+}$cell fate following our previously reported stepwise differentiation protocol (see Methods, pancreatic $\beta$-cell differentiation protocol $1)$ : generating first $\mathrm{SOX}_{17}+/ \mathrm{FOXA} 2^{+}$definitive endoderm, followed by $\mathrm{PDX}^{+} / \mathrm{NKX} 6.1^{+}$pancreatic progenitors and finally $\mathrm{PDX}^{+} / \mathrm{INS}^{+}$cells (Fig. $1 \mathrm{a}$ and Supplementary Fig. 1a) ${ }^{18}$. The differentiated cell population containing $\sim 25 \% \mathrm{INS}^{+}$cells and $\sim 75 \%$ INS $^{-}$cells were dissociated and re-plated on laminin $\mathrm{V}$-coated 384-well plates for the chemical screen. The goal was to identify compounds that target a relative loss of the INS $^{+}$cells.
The Phase I Toxicity Forecaster (ToxCast) library provided by the U.S. Environmental Protection Agency (EPA) was used, which represents $\sim 2000$ compounds, including pesticides, industrial and consumer products. After overnight incubation, the chemicals were added at $20 \mathrm{nM}, 200 \mathrm{nM}, 2 \mu \mathrm{M}$, and $20 \mu \mathrm{M}$ (detailed screening protocol and library information is described in the Methods). After $96 \mathrm{~h}$ of treatment, the cells were stained with an insulin antibody and analyzed using an ImageXpress ${ }^{\mathrm{MICRO}}$ Automated High-Content Analysis System. The chemicals that caused more than $60 \%$ reduction in the survival rate of INS $^{+}$ cells, while affecting $<20 \%$ loss of the INS $^{-}$cells were picked as primary hits (Fig. 1a and Supplementary Fig. 1b). Two hit compounds were confirmed, including a rodenticide called $N-3$ pyridylmethyl- $N^{\prime \prime}$-4-nitrophenyl urea (Vacor) (Fig. 1b) that had previously been shown to be toxic to human pancreatic $\beta$-cells ${ }^{19}$, and a pesticide, 2-(4-tert-butylphenoxy)-cyclohexyl prop-2-yne1-sulfonate (propargite) (Fig. 1b). The lower $\mathrm{IC}_{50}$ of both propargite and Vacor for INS $^{+}$cells as compared to INS $^{-}$cells confirmed that these hit compounds specifically decreased the survival of $\mathrm{INS}^{+}$cells (propargite: $\mathrm{IC}_{50}=1.09 \mu \mathrm{M}$ for $\mathrm{INS}^{+}$cells; $\mathrm{IC}_{50}=9.83 \mu \mathrm{M}$ for $\mathrm{INS}^{-}$cells; Vacor: $\mathrm{IC}_{50}=4.89 \mu \mathrm{M}$ for $\mathrm{INS}^{+}$ cells; $\mathrm{IC}_{50}=61.56 \mu \mathrm{M}$ for $\mathrm{INS}^{-}$cells, Fig. 1c). Since Vacor has been banned by the EPA since 1979, we focused on the stillcommonly used pesticide, propargite.

Using a related protocol recently published by our group ${ }^{20}$ (see Methods, pancreatic $\beta$-cell differentiation protocol 2), hESCs were differentiated to glucose-responsive, pancreatic $\beta$-like cells (Supplementary Fig. 1c, d) to further examine the toxicity of propargite. Consistent with the primary screening results, propargite specifically decreased the number of glucose-responsive, pancreatic $\beta$-like INS $^{+}$cells in a dose-dependent manner (Fig. 1d, e). To determine whether propargite functioned through the induction of cell death, by affecting cell proliferation, or by the inhibition of $\beta$-cell differentiation, live cell-imaging was applied to monitor in real-time the survival of INS-GFP ${ }^{+}$cells derived from $I N S^{G F P / W}$ HES3 hESCs, which is an INS-GFP hESC reporter line ${ }^{21}$. INS-GFP ${ }^{+}$cells gradually disappeared during the 4 days of propargite treatment, while the population of DMSO-treated INS-GFP ${ }^{+}$cells did not change significantly (Fig. 1f, g). To exclude the possibility that propargite decreased the number of $\mathrm{INS}^{+}$cells by affecting cell proliferation, DMSO and propargite-treated hESC-derived INS ${ }^{+}$cells were stained for Ki67, a cell proliferation marker. Propargite did not affect the percentage of $\mathrm{Ki}^{+} / \mathrm{INS}^{+}$cells (Supplementary Fig. 1e, f). Due to the low proliferation rate of $\mathrm{INS}^{+}$cells, we further examined the effect of propargite on MIN6 cells, a mouse pancreatic $\beta$-cell line that displays robust proliferation. Propargite-induced MIN6 cell death in a dose-dependent manner with $\mathrm{IC}_{50}=1 \mu \mathrm{M}$ (Supplementary Fig. 1g), consistent with the effect on hESCderived INS $^{+}$cells. No significant difference was detected between DMSO and $1.6 \mu \mathrm{M}$ propargite-treated MIN6 cells regarding the percentage of $\mathrm{Ki} 67^{+} / \mathrm{INS}^{+}$cells after 4 days of treatment (Supplementary Fig. 1h, i), further validating that propargite does not function through blocking cell proliferation. Finally, primary human islets were treated for 4 days with DMSO or propargite and subsequently stained with propidium iodide (PI) to detect dead cells. Consistent with the effect on hESCderived INS $^{+}$cells, propargite decreased the number of INS ${ }^{+}$ cells (Fig. 1h, i), accompanied with an increased percentage of $\mathrm{PI}^{+} / \mathrm{INS}^{+}$cells in INS ${ }^{+}$cells of primary human islets (Fig. 1h, j).

Propargite induces $\beta$-cell necrosis preceded by DNA damage. RNA-seq was used to compare global transcript expression profiles between DMSO and propargite-treated INS-GFP ${ }^{+}$cells derived from INS ${ }^{\mathrm{GFP} / \mathrm{W}}$ HES3 cells. Gene ontology pathway 
a

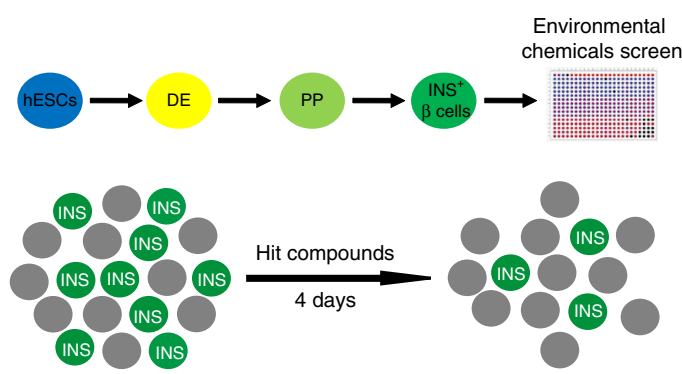

b
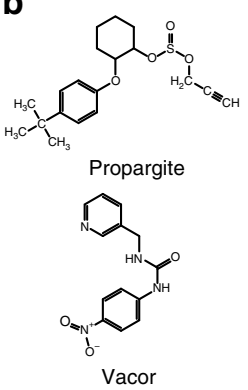

C

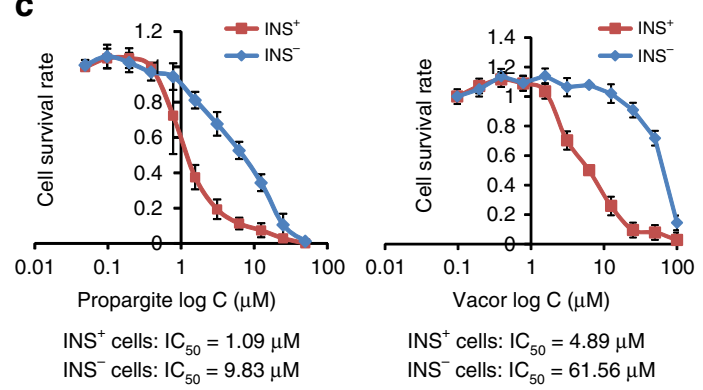

d

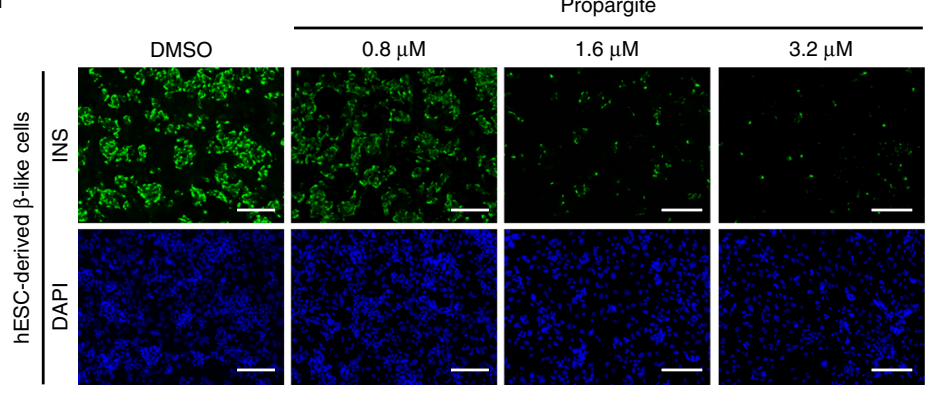

e

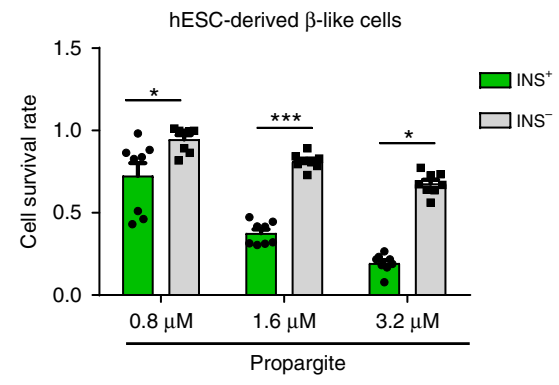

f

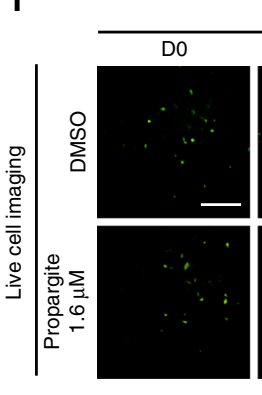

INS $^{\text {GFP/W }}$ HES3-derived INS-GFP ${ }^{+}$cells
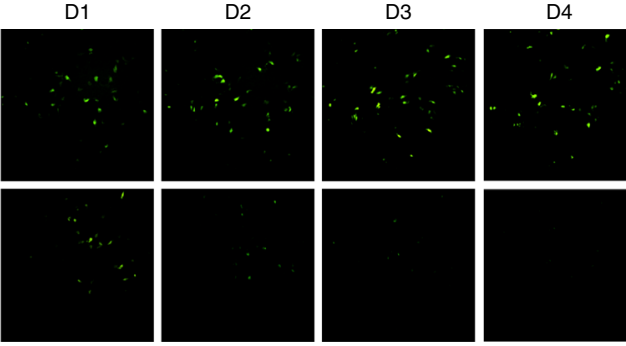

h

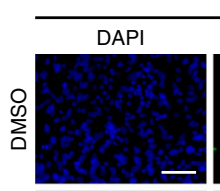

Human islets
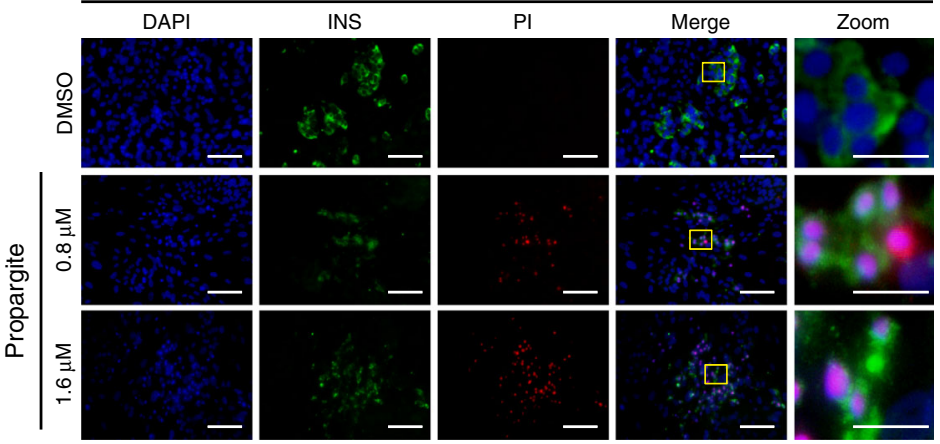

g

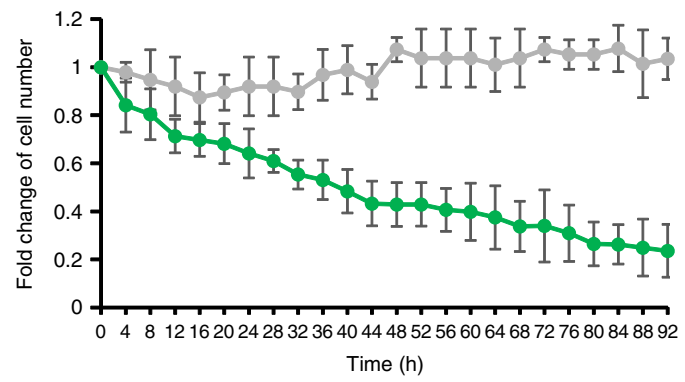

Time (h)

$\longrightarrow$ DMSO $\longrightarrow$ Propargite $1.6 \mu \mathrm{M}$

i
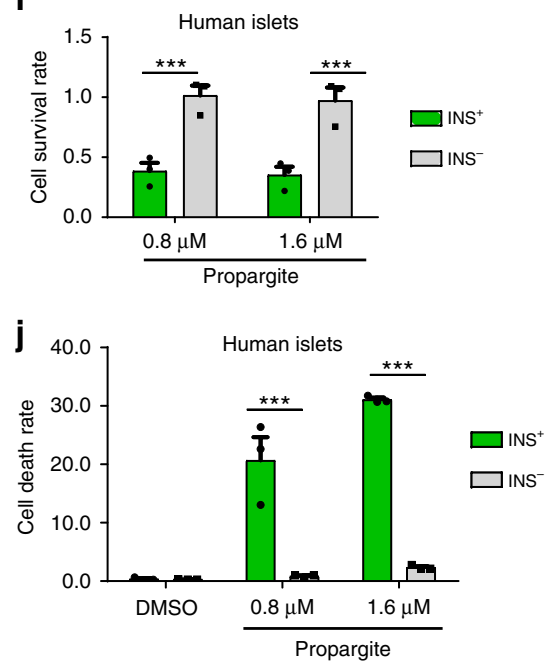

analysis showed "regulation of DNA-dependent transcription" among the top downregulated pathways upon Propargite treatment (Fig. 2a). In contrast, genes associated with chromatin assembly and cell death-related processes were upregulated under those conditions (Fig. 2a). Several genes that were highly upregulated (fold-change $>3$ ) in the propargite-treated cells were related to DNA damage, including, DNA damage-inducible transcript 3 (DDIT3) and the growth arrest and DNA damageinducible alpha (GADD45A or DDIT1) (Supplementary Fig. 2a and Table 1). The upregulation of these genes was further confirmed by qRT-PCR analysis (Fig. 2b). Propargite-treated MIN6 cells were next examined using a well-established DNA damage marker, phospho-histone H2A.X $(\gamma \text {-H2A.X })^{22}$. Western blotting confirmed that propargite-induced $\gamma$-H2A.X expression in a 
Fig. $1 \mathrm{~A}$ high-content screen identifies propargite as a compound that induces pancreatic $\beta$-cell death. a Scheme of pancreatic $\beta$-cell differentiation and high-content chemical screen. $\mathbf{b}$ Chemical structure of two hit compounds: Propargite and Vacor. c Inhibitory curve and IC 50 of propargite or Vacor on INS $^{+}$and INS ${ }^{-}$cells $(n=8)$. d, e Immunocytochemistry analysis $(\mathbf{d})$ and survival rate $(\mathbf{e})$ of H1-derived glucose-responding INS ${ }^{+}$and INS ${ }^{-}$cells treated with different doses of propargite $(n=8)$. Pancreatic $\beta$-like cells were stained for INS (green) and all cells were counterstained by DAPI (blue). Scale bars, $100 \mu \mathrm{m}$. The survival rate was calculated by dividing the average number of cells in propargite-treated conditions by the average number of cells in the DMSO control. $\mathbf{f}, \mathbf{g}$ Representative live images (f) and fold-change ( $(\mathbf{g})$ of INSW/GFP HES3-derived INS-GFP ${ }^{+}$cells treated with $1.6 \mu M$ propargite or DMSO control at different time points compared to initial time $O(n=3)$. Scale bars, $100 \mu \mathrm{m}$. $\mathbf{h}, \mathbf{i}, \mathbf{j}$ Representative images $(\mathbf{h})$ and cell survival rate $(\mathbf{i})$ or cell death rate $(\mathbf{j})$ of DMSO or propargite-treated human primary islets $(n=3)$. Pancreatic $\beta$-cells were stained with the INS antibody (green) and dead cells were stained with propidium iodide (PI) (red). Scale bars, $200 \mu \mathrm{m}$. Scale bars for higher resolution (Zoom) images, $800 \mu \mathrm{m}$. Pancreatic $\beta$-cell death rate was calculated by defining percentages of $\mathrm{INS}^{+} \mathrm{PI}^{+}$cells in $\mathrm{INS}^{+}$cells, and non- $\beta$-cell death rate was calculated by percentages of $\mathrm{INS}^{-} \mathrm{PI}^{+}$cells in $\mathrm{INS}^{-}$ cells. Values presented as mean \pm S.D. n.s. indicates a non-significant difference. $p$ values calculated by unpaired two-tailed Student's $t$-test were ${ }^{\star} p<0.05$, ${ }^{\star \star \star} p<0.001$. Related to Supplementary Fig. 1

dose-dependent and time-dependent manner (Fig. 2c), indicating that propargite induces DNA damage in pancreatic $\beta$-cells.

To define the mechanism of propargite-induced cell death, propargite-treated $\beta$-like cells were examined for apoptosis, necrosis, and autophagy ${ }^{23}$. First, flow cytometry was used to examine phosphatidylserine (PS) translocation with antiAnnexin- $\mathrm{V}$ antibodies, and immunocytochemistry was used to determine caspase- 3 activation. Propargite induced neither PS translocation (Supplementary Fig. 2b, c) nor caspase-3 activation (Supplementary Fig. 2d, e), which indicates that apoptosis is not the primary cause of propargite-induced $\beta$-cell death. Second, in western blotting experiments we found no significant increase in the relative levels of LC3-II, a widely used marker of autophagy, in propargite-treated MIN6 cells, suggesting that propargite does not function through inducing autophagy (Supplementary Fig. 2f $)^{24}$. Finally, we measured extracellular amounts of high mobility group B1 (HMGB1) protein, which is chromatin-bound under normal circumstances and released into the extracellular milieu when a cell undergoes necrosis ${ }^{25,26}$. Western blotting experiments detected extracellular HMGB1 as early as 1 day after propargite treatment, and the levels increased progressively over time. Additionally, the levels of extracellular HMGB1 were elevated in a dose-response manner to propargite while intracellular HMGB1 levels decreased or remained constant (Fig. 2d). To further validate necrosis as the cause of cell death, a time course experiment was performed, revealing that $\gamma$-H2A.X was induced $12 \mathrm{~h}$ after treatment of MIN6 cells, before the detection of extracellular HMGB1 at $18 \mathrm{~h}$ after treatment (Fig. 2e). Thus, propargite initiates DNA damage on $\beta$-cells and subsequently causes cell death by necrosis.

$\beta$-cells are sensitive to propargite due to low glutathione. A previous study found that in rats propargite and propargiteimmediate metabolites directly conjugated with glutathione (GSH) before glutathione S-transferases (GST) enzyme detoxification and degradation (http://www.fao.org/fileadmin/ templates/agphome/documents/Pests_Pesticides/JMPR/

Evaluation02/propargiteevaljj.pdf). To determine whether the hypersensitivity of INS $^{+}$pancreatic $\beta$-cells was due to low glutathione (GSH) levels, the endogenous GSH levels were measured in hESC-derived INS-GFP $^{+}$and INS $^{-}$cells, primary human islets, and $\mathrm{BJ}$-fibroblasts. The INS-GFP ${ }^{+}$cells and human islets had significantly lower GSH levels compared to those of INS ${ }^{-}$ and fibroblast cells (Fig. 2f). To determine whether low GSH levels caused hypersensitivity to propargite treatment, GSH was added to cultured cells in an attempt to rescue propargite-induced $\beta$-cell toxicity. Indeed, $2 \mathrm{mM} \mathrm{GSH}$ fully rescued the survival rate of INS ${ }^{+}$cells after propargite treatment (Fig. $2 \mathrm{~g}, \mathrm{~h}$ ). In addition, GSH also rescued the propargite-induced pancreatic $\beta$-cellspecific death in human islets (Fig. 2i, j). Furthermore, RNAseq profiles showed that GSH reversed propargite-induced global transcriptional changes (Fig. 2k, l), including the down-regulation of genes related to pancreas function and the upregulation of genes associated with cell death (Supplementary Fig. 3a). Additionally, GSH fully rescued propargite-induced DNA damage (indicated by $\gamma$-H2A.X expression levels) and partially rescued propargite-induced necrosis, as indicated by extracellular HMGB1 protein levels (Fig. 2m). Since GSH is an important antioxidant, the propargite-treated MIN6 cells were monitored for reactive oxygen species (ROS) (Supplementary Fig. 3b). However, we did not find any increase of ROS in propargite-treated conditions, suggesting the effect of GSH on rescuing $\beta$-like cells from propargite-induced necrosis was not due to its antioxidative properties. Previous findings in rodents reported on a GSHdependent propargite detoxification pathway (Supplementary Fig. 3c), suggesting that a similar mechanism may apply to its action in pancreatic $\beta$-cells.

GSTT1 $^{-/-} \beta$-cells show increased susceptibility to propargite. We next sought to test whether the genetic background of $\beta$-like cells affects their response to propargite-induced toxicity, with a particular interest in whether diabetes-associated gene variants could impact their sensitivity. Based on the proposed mode-ofaction of propargite, the genes encoding GSTs, a family of phase II metabolic isozymes, known for the ability to catalyze the conjugation GSH to xenobiotic substrates (Supplementary Fig. 3c $)^{27}$, is a strong candidate to consider. Among more than six different types of cytosolic GSTs ${ }^{27}$, the polymorphic homozygous deletions of GST mul (GSTM1) and GST theta1 (GSTT1) occurs with a frequency of $\sim 40-60 \%$ and $\sim 13-25 \%$, respectively, in Caucasian populations ${ }^{28}$. GWAS data suggest that this GSTT1null and GSTM1-null genotype are associated with increased risk of diabetes ${ }^{29-31}$. Therefore, we performed a small population study using pancreatic $\beta$-like cells derived from three hESCs and seven hiPSCs. Indeed, hESC/iPSC derived pancreatic $\beta$-like cells displayed variable survival rates in the presence of $1.6 \mu \mathrm{M}$ propargite treatment (Fig. 3a). Genotyping of the GSTM1 and GSTT1 genes by PCR showed that of the ten cell lines four are null for both GSTM1 and GSTT1, and 2 are null for GSTM1 only, consistent with the heterogeneity of GSTM1 and GSTT1 expression in the human genome (Fig. 3a). A correlation study was performed to compare the survival rates of INS $^{+}$cells derived from these lines following propargite treatment. The $\mathrm{INS}^{+}$cells from those lines lacking both genes have significantly lower survival rates compared to cells derived from those lines having at least the GSTT1 gene present (Fig. 3b), while GSTM1-null pancreatic $\beta$-like cells did not show significantly lower survival rates compare to lines with an intact GSTM1 gene (Fig. 3c). To further validate these results in an isogeneic background, GSTM1 $1^{-/-}$and GSTT1 $^{-/-}$hESCs were established using a CRIPSR-based genome editing approach in the $\mathrm{H} 1$ parental cell background. Considering potential variation between different 
a

\begin{tabular}{|c|c|c|}
\hline & Gene ontology biological process & $\begin{array}{l}\text { Benjamini } \\
q \text { value }\end{array}$ \\
\hline \multirow{5}{*}{$\begin{array}{l}\text { Decreased in } \\
\text { propargite treated } \\
\text { HES3-derived } \\
\text { INS-GFP }^{+} \text {cells }\end{array}$} & Regulation of transcription, DNA-dependent & 0.00000013 \\
\hline & Glycoprotein metabolic process & 0.0086 \\
\hline & Response to glucose stimulus & 0.064 \\
\hline & Pancreas development & 0.079 \\
\hline & Aminoglycan metabolic process & 0.19 \\
\hline \multirow{5}{*}{$\begin{array}{l}\text { Enriched in } \\
\text { propargite treated } \\
\text { HES3-derived } \\
\text { INS-GFP }^{+} \text {cells }\end{array}$} & Chromatin assembly & 0.00000029 \\
\hline & Anti-apoptosis & 0.000015 \\
\hline & Response to organic substance & 0.000013 \\
\hline & Cell death & 0.00098 \\
\hline & Regulation of cell size & 0.011 \\
\hline
\end{tabular}

b

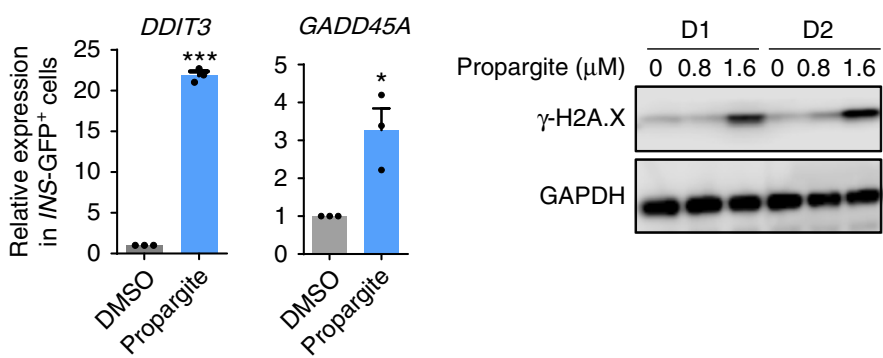

d

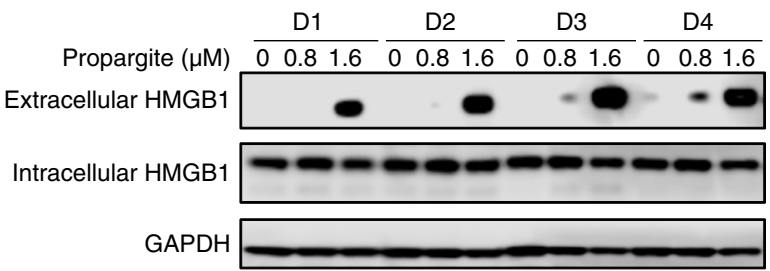

e

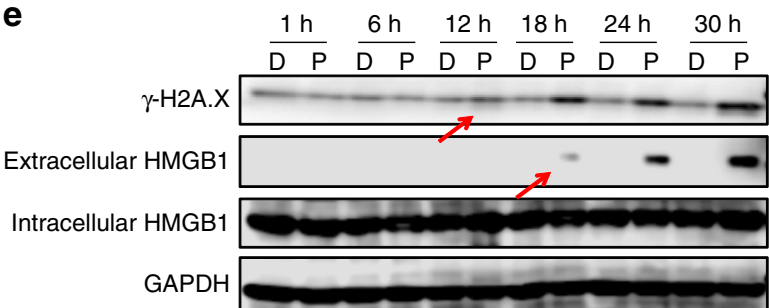

h

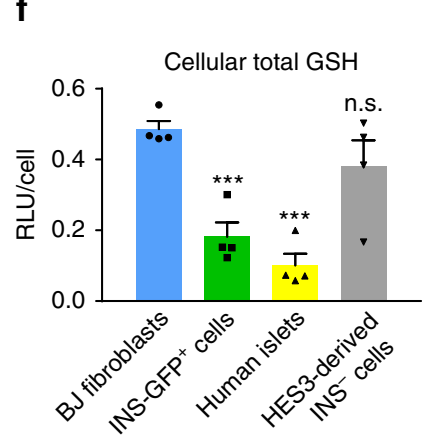

g
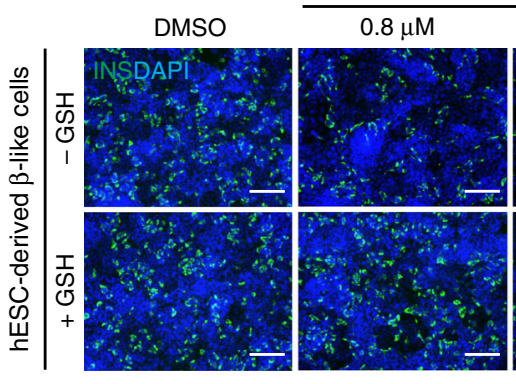

Propargite

$1.6 \mu \mathrm{M}$

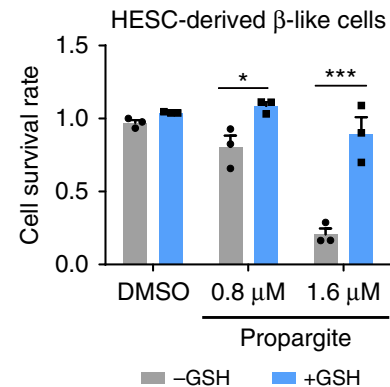

$\mathbf{k}$

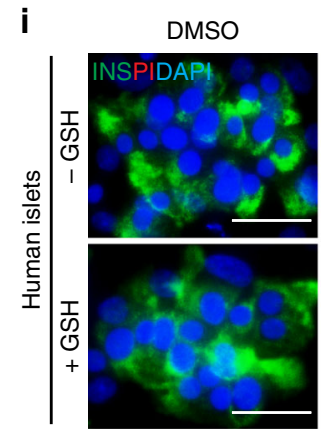

Propargite $0.8 \mu \mathrm{M}$
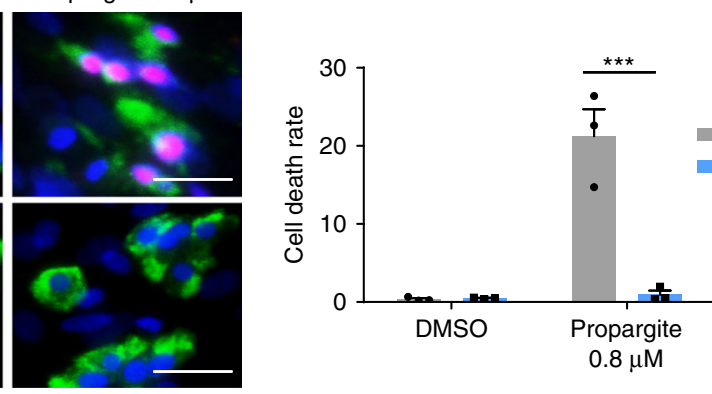

$-\mathrm{GSH}$

$+\mathrm{GSH}$

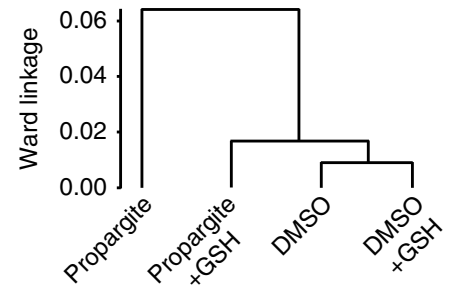

I

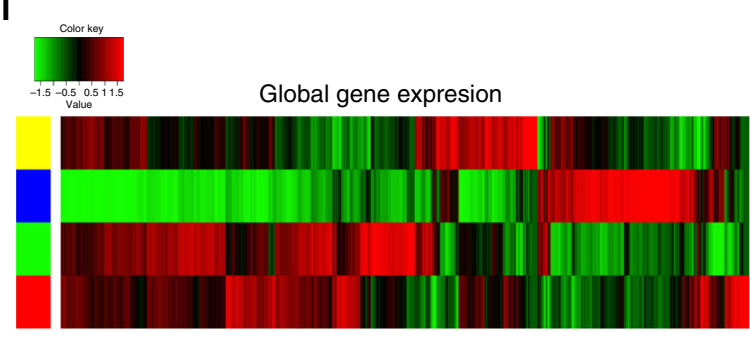

Propargite+GSH

Propargite

DMSO+GSH

DMSO

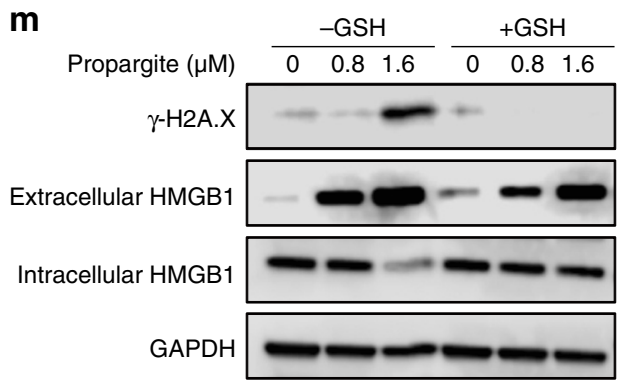

hESC clones, two clones from each line were chosen for further analysis. Biallelic indel mutations for each of the targeted genes were validated by genomic DNA sequencing (Supplementary Fig. 3d, e). The two GSTT1 knockout clones were both homozygous null mutants, and the two GSTM1 knockout clones were both compound-null mutants. Each indel mutation created an early frameshift that generated null alleles as confirmed by western blotting experiments in mutant hESC-derived cells (Fig. 3d).

The wild type (WT), GSTM1 ${ }^{-/-}$, and GSTT1 $1^{-/-}$hESCs had similar capacities to differentiate into $\mathrm{INS}^{+}$cells as monitored by intracellular FACS (Fig. 3e), suggesting that the GSTM1 $1^{-/-}$and $\mathrm{GSTT1}^{-/-}$mutations did not affect differentiation to $\mathrm{INS}^{+}$cells. 
Fig. 2 Propargite induces glutathione (GSH)-dependent $\beta$-cell necrosis preceded by DNA damage. a Top five significantly upregulated and downregulated biological processes identified by RNA-seq profiles in propargite-treated INSW/GFP HES3-derived INS-GFP ${ }^{+}$cells. b qRT-PCR analysis of DDIT3 and GADD45A in DMSO or propargite-treated INS-GFP+ cells $(n=3)$. c Western blotting analysis of $\gamma$-H2A.X in MIN6 cells treated with propargite. $\mathbf{d}$ Western blotting analysis of necrosis marker (extracellular HMGB1) in MIN6 cells treated with propargite. e Time course western blotting analysis of extracellular HMGB1 and $\gamma$-H2A.X of MIN6 cells treated with DMSO (D) or propargite (P) during a period of 1 to $30 \mathrm{~h}$. GAPDH was used as a loading control in all the western blots. Red arrows indicate initiation of propargite-induced changes. $\mathbf{f}$ Total GSH levels in human fibroblasts, INSW/GFP HES3-derived INS ${ }^{+}$cells, INS- cells and human islets $(n=4) . \mathbf{g}$, $\mathbf{h}$ Representative images $(\mathbf{g})$ and cell survival rate $(\mathbf{h})$ of DMSO or propargite-treated H1-derived INS+ cells in the presence of absence of $2 \mathrm{mM} \mathrm{GSH}(n=3)$. Scale bars, $100 \mu \mathrm{m}$. $\mathbf{i}, \mathbf{j}$ Representative images (i) and cell death rate (j) of DMSO or propargite-treated human islets in the presence or absence of $2 \mathrm{mM} \mathrm{GSH}(n=3)$. Scale bars, $800 \mu \mathrm{m}$. $\mathbf{k}$, I Hierarchical clustering (k) and heatmap (I) of transcriptional profiles in INSW/GFP HES3-derived INS-GFP+ cells treated with DMSO, DMSO $+2 \mathrm{mM} \mathrm{GSH}, 1.6 \mu \mathrm{M}$ propargite, or $1.6 \mu \mathrm{M}$ propargite $+2 \mathrm{mM}$ GSH. $\mathbf{m}$ Western blotting analysis of extracellular HMGB1 and $\gamma-\mathrm{H} 2 \mathrm{~A}$.X in propargite-treated MIN6 cells on day 4 . Values presented as mean \pm S.D. n.s. indicates a non-significant difference. $p$ values calculated by unpaired two-tailed Student's $t$-test were ${ }^{\star} p<0.05,{ }^{\star \star} p<0.001$. Related to Supplementary Figs. 2 and 3

To generate propargite inhibitory curves, cells derived from the WT, GSTM1 $1^{-1-}$ or GSTT1 $^{-1-}$ hESCs were treated with propargite at increasing concentrations. The $\mathrm{IC}_{50}$ value of propargite for the GSTT1 ${ }^{-1}$ INS ${ }^{+}$cells (but not the GSTM1 $^{-/-}$INS $^{+}$cells) was significantly lower than that of the WT INS ${ }^{+}$cells $\left(\mathrm{IC}_{50}=1.17 \mu \mathrm{M}\right.$ for $\mathrm{GSTT1}^{-/-}-1 \mathrm{INS}^{+}$cells; $\mathrm{IC}_{50}$ $=2.15 \mu \mathrm{M}$ of GSTT1 $^{+/+}-1 \mathrm{INS}^{+}$cells) (Fig. $3 \mathrm{f}$ ). Meanwhile, lower survival rates were accompanied by significantly higher levels of DNA damage in the cells as determined by the percentages of $\gamma$ $\mathrm{H}_{2} \mathrm{AX}^{+} \mathrm{INS}^{+} / \mathrm{INS}^{+}$cells (Fig. 3g, h). Together, these results indicate that GSTT1 gene deletion increases the susceptibility of INS $^{+}$cells to propargite-induced cell death. To further confirm our results in mature human pancreatic $\beta$-cells, we used a human $\beta$-cell line, EndoC- $\beta \mathrm{H} 1$ cells $^{32}$, that was confirmed positive for the GSTT1 gene (Supplementary Fig. 3f). The cells were infected with a lentivirus expressing the Cas9 gene and two sgRNAs targeting different locations of exon 4 in the GSTT1 gene (Supplementary Table 2 and 3). Loss of GSTT1 protein expression in EndoC- $\beta \mathrm{H} 1$ cells carrying sgGSTT1 was confirmed by western blotting experiments (Fig. 3i). EndoC- $\beta \mathrm{H} 1$ cells carrying sgGSTT1 were subsequently cultured in the presence or absence of propargite and analyzed with PI staining. Consistent with $G S T T 1^{-1-}$ hESCderived INS $^{+}$cells, a significant increase of INS $^{+}$cell death was detected in EndoC- $\beta \mathrm{H} 1$ cells expressing sgGSTT1 (Fig. 3j, k). Accordingly, our results point to the fact that the toxicity of propargite is strongly modulated by the host cell genetic background.

Midbrain dopamine neurons are hypersensitive to propargite. Next, we determined whether propargite is toxic to other cell types by treating a range of different $\mathrm{hESC}$-derived lineages with $1.6 \mu \mathrm{M}$ of propargite, including $\mathrm{CD} 29^{+} / \mathrm{CD} 73^{+}$mesenchymal stem cells, $\mathrm{CTNT}^{+}$cardiomyocytes, $\mathrm{AlAT}^{+}$hepatocytes, $\mathrm{HuC} / \mathrm{D}^{+}$neurons and primary BJ-fibroblasts (Supplementary Fig. 4a-e). While most cell types exhibited a low sensitivity to propargite, we found that $\mathrm{HuC} / \mathrm{D}^{+}$neurons were highly susceptible to propargite similar to the results obtained in $\beta$-cells (Supplementary Fig. 4f-h). This raised the question whether propargite exposure could be associated with neurodegenerative disease.

An epidemiological study has reported that high levels of wellwater contamination with propargite is associated with an increased prevalence of Parkinson's disease in the affected region ${ }^{33}$. Parkinson's disease is characterized by the specific loss of midbrain dopamine (mDA) neurons $s^{34,35}$. Therefore, we hypothesized that $\mathrm{mDA}$ neurons may be particularly sensitive to propargite toxicity. To test this hypothesis, we derived $\mathrm{TH}^{+}$ $/$ FOXA $2^{+}$mDA neurons and $\mathrm{MAP}^{+} / \mathrm{CTIP}^{+}$cortical neurons from hESCs using differentiation conditions published previously by our group ${ }^{36,37}$ (Fig. 4a and Supplementary Fig. 5a-c). Cell survival data showed that $\mathrm{mDA}$ neurons were dramatically more sensitive to propargite than cortical neurons resulting in significant $\mathrm{mDA}$ neuron cell death when treated with concentrations at 1 and $3 \mu \mathrm{M}$ (Fig. $4 \mathrm{~b}$ ). We next examined whether propargite-induced toxicity in mDA neurons acts via a mechanism similar to that observed for $\beta$-cell death. Indeed, GSH was able to rescue $\mathrm{mDA}$ neuron death in response to propargite treatment (Fig. 4c, d) by preventing both DNA damage and cell necrosis (Fig. 4e, f). Additionally, GSTT1 ${ }^{-/-}$hESC-derived mDA neurons, assessed by the expression of FOXA2, were more sensitive to propargite than matched $\mathrm{FOXA}_{2}{ }^{+}$neurons derived from isogenic GSTT1 $1^{+/+}$or GSTM1 ${ }^{-/-}$hESCs, consistent with the data using $\beta$-cells (Fig. $4 \mathrm{~g}$ and Supplementary Fig. 5d). Analysis of published gene expression data from substantia nigra tissue of PD patients ${ }^{38}$ shows a decrease in expression levels for GSTT1 but not GSTM1, compared to age-matched controls (Fig. 4h). This suggests that a decreased GSTT1 level is a potential risk factor for $\mathrm{PD}$, mediated by responses to environmental stimuli. Collectively, our results indicate that propargite exerts very similar effects in both $\beta$-cells and $\mathrm{mDA}$ neurons, and the findings provide a potential mechanism for how increased propargite levels in the drinking water may increase the prevalence of diabetes or $\mathrm{PD}^{39}$.

GSTT1 $^{-/-} \beta$-cells are hypersensitive to propargite in vivo. To investigate whether $\beta$-cell toxicity is caused by propargite in vivo, CD-1 mice were treated with different doses of propargite or corn oil (vehicle) daily for 5 days via intraperitoneal injection. $12 \mathrm{mg} / \mathrm{kg}$ propargite treatment lightly increased blood glucose level without significantly affecting body weight (Supplementary Fig. 6a, b). Meanwhile, it led to a significant reduction of insulin levels in the plasma of the fasted mice (Fig. 5a). A significant increase of the percentage of $\gamma-\mathrm{H}_{2} \mathrm{AX}^{+} / \mathrm{INS}^{+}$in $\mathrm{INS}^{+}$cells of propargite-treated mice was also observed, suggesting enhanced rates of propargite-induced DNA damage in mouse pancreatic $\beta$ cells in vivo (Fig. 5b, c). To investigate the effect of propargite on human pancreatic $\beta$-cells in vivo, we infected EndoC- $\beta \mathrm{H} 1$ cells with a lentivirus carrying constitutively expressed luciferase to generate the luciferase-expressing EndoC- $\beta \mathrm{H} 1$ cells (EndoC- $\beta \mathrm{H} 1-$ Luc cells). The EndoC- $\beta$ H1-Luc cells were then transplanted into NSG immune-deficient mice to create a humanized mouse model (Fig. 5d). The humanized mice were administrated with $12 \mathrm{mg} / \mathrm{kg}$ propargite. In vivo imaging for luciferase signal showed that luciferase signals from control EndoC- $\beta \mathrm{H} 1$-Luc cells increased gradually during the 5-day course. In contrast, the signal of cells in the propargite administered mice showed a slower rate increase at day 3 and a marked decrease at day 5 (Fig. 5e and Supplementary Fig. 6c). To further confirm that the sensitivity of $\beta$-cells to propargite depends on genetic background, EndoC- $\beta \mathrm{H} 1-\mathrm{Luc}$ cells carrying sgGSTT1 were transplanted into the immune- 

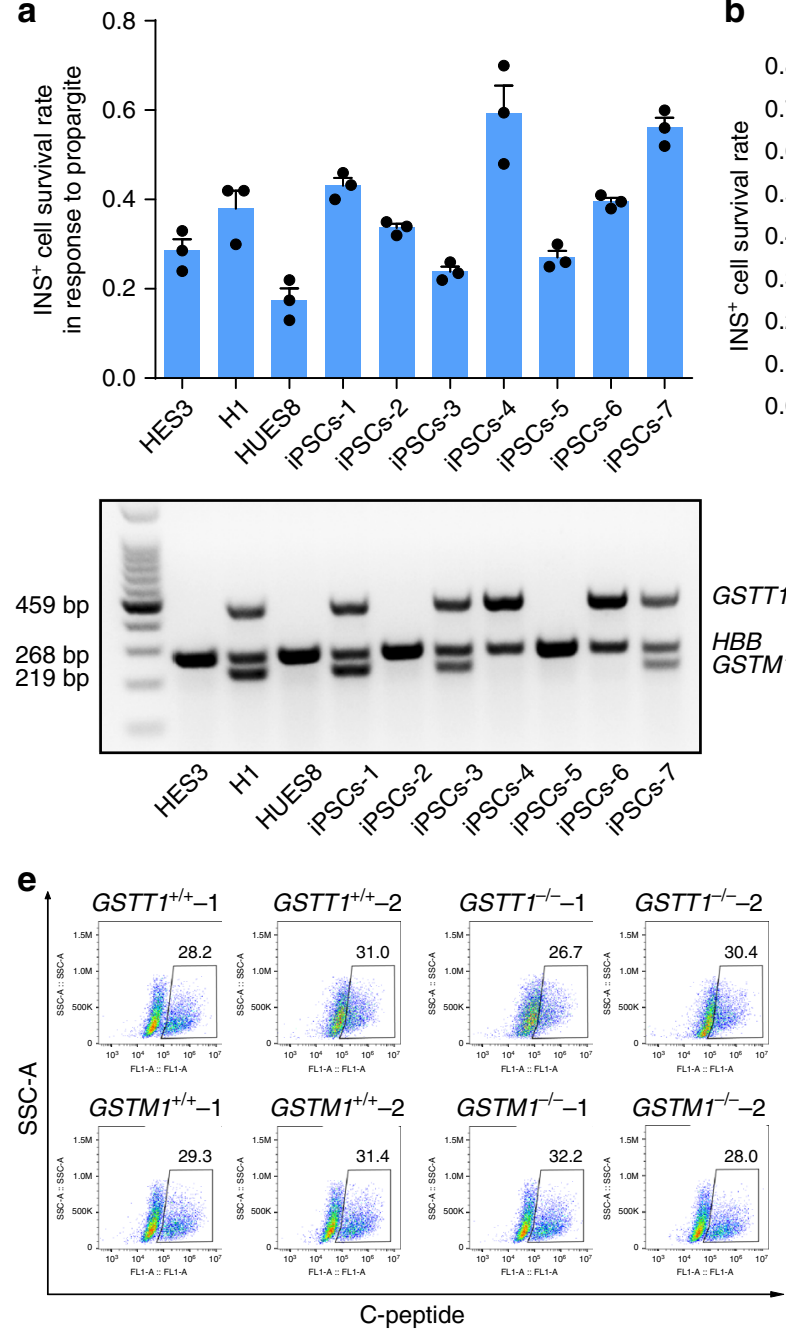

g
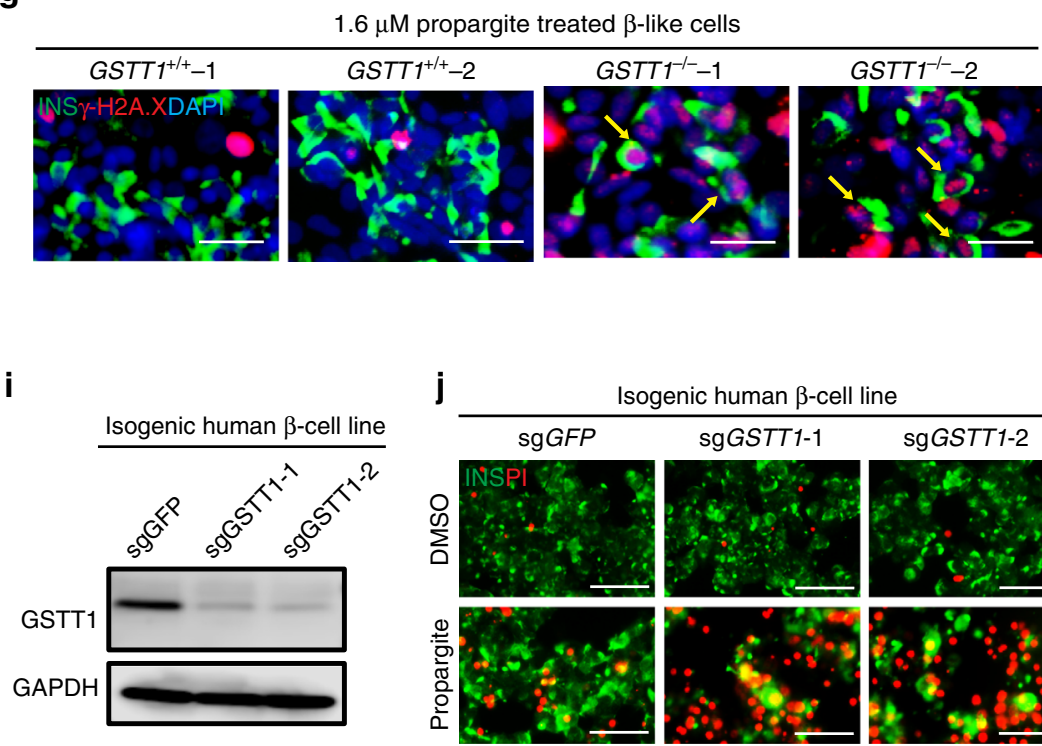

sogenic human $\beta$-cell line

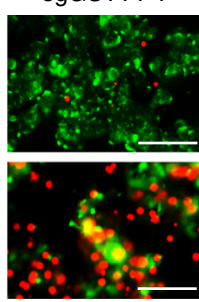

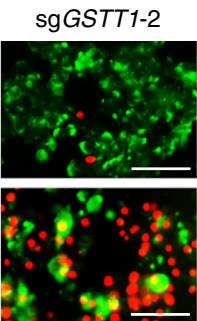

C

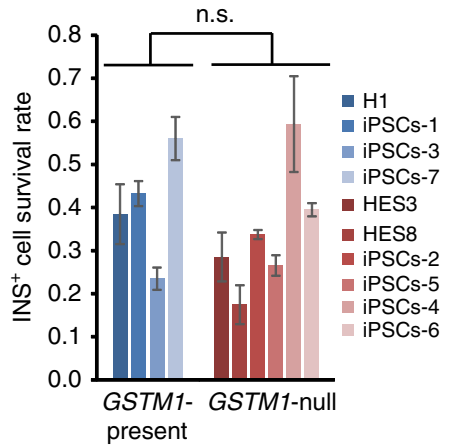

Isogenic hESCs
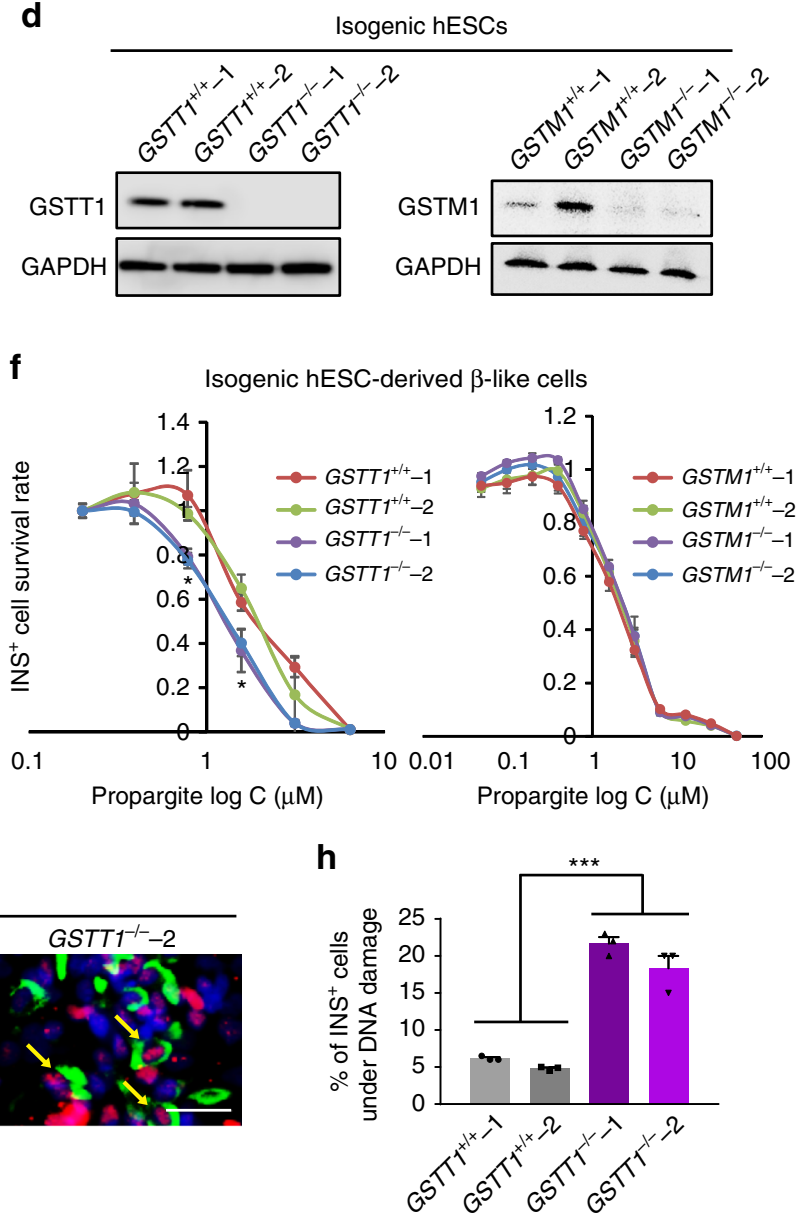

$\mathbf{k}$

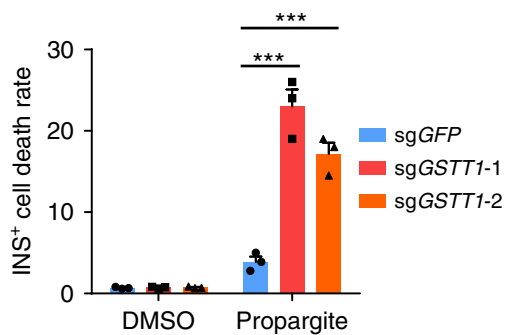

deficient mice. EndoC- $\beta \mathrm{H} 1-\mathrm{Luc}$ cells carrying sgGFP were used as a control. At day 3, the survival rate of the EndoC- $\beta$ H1-Luc cells carrying sgGSTT1 was associated with higher cell death rate upon propargite treatment as measured with TUNEL assays (Fig. $5 \mathrm{f}, \mathrm{g}$ ). Together, the data indicate that $G S T T 1^{-/-}$pancreatic $\beta$-like cells are hypersensitive to propargite in vivo.

\section{Discussion}

GWAS have identified an increasing number of diabetesassociated genes, yet only a small proportion of individuals harboring these genomic variables progress to clinical disease. This implies that additional factors such as environmental influences, may drive disease initiation and progression in genetically 
Fig. 3 A hPSC-based population study discovers that GSTT1-null pancreatic $\beta$-like cells are hypersensitive to propargite-induced cell death. a Survival rate of INS $^{+}$cells derived from 10 different hESC or iPSC lines cultured in the presence of $1.6 \mu \mathrm{M}$ propargite $(n=3)$, and genotype analysis of GSTM1 and GSTT1 in those hESCs and iPSCs. b, c Correlation of INS ${ }^{+}$cell survival rate in the presence of $1.6 \mu$ M propargite in cells lacking both GSTM1 and GSTT1 (b), or lacking only GSTM1 (c). n.s. indicates a non-significant difference. d Western blotting analysis of GSTT1 or GSTM1 protein expression in INS+ cells derived from isogenic wild type, GSTT1-/- or GSTM1-/- H1 hESCs. The -/- null clones were CRSIPR-induced biallelic frameshift mutants. The two GSTT1 knockout clones were both homozygous null mutants, and the two GSTM1 knockout clones were both compound-null mutants. e Flow cytometry analysis of C-peptide ${ }^{+}$cells in isogenic GSTT1-/- or GSTM1-/- hESC-derived D18 cells. f Inhibition curve of propargite on INS + cells derived from GSTT1+/+ or GSTT1 $-/-\mathrm{H} 1 \mathrm{hESCS}(n=3) . \mathbf{g}$, h Representative images $(\mathbf{g})$ and DNA damage rate $(\mathbf{h})$ of GSTT1 ${ }^{+/}+$and GSTT1 ${ }^{-/-} \beta$-like cells $(n=3)$. Scale bars, $800 \mu \mathrm{m}$. $\gamma^{-}$ H2A.X+/INS + cells are highlighted with yellow arrows. $\mathbf{i}$ Western blot analysis of GSTT1 protein in EndoC- $\beta$ H1 cells carrying sgGSTT1. Two CRISPR gRNAs ( $s g$ GSTT1-1 and sgGSTT1-2) were used for generating GSTT1-/- EndoC- $\beta \mathrm{H} 1$ cells. $\mathbf{j}, \mathbf{k}$ Representative images (j) and cell death rate (k) of GSTT1 ${ }^{-/}-$EndoC$\beta \mathrm{H} 1$ cells treated with $1.6 \mu \mathrm{M}$ propargite $(n=3)$. Scale bars, $200 \mu \mathrm{m}$. Values presented as mean \pm S.D. n.s. indicates a non-significant difference. $p$ values calculated by unpaired two-tailed Student's $t$-test were ${ }^{\star} p<0.05,{ }^{\star \star \star} p<0.001$. Related to Supplementary Fig. 3

predisposed subjects. To model this scenario, we performed an unbiased high-content chemical screen and identified propargite, which induced pancreatic $\beta$-cell-specific death. The ubiquity of propargite as a common pesticide in pediatric patients is made clear by an NIH report stating that the average daily intake of propargite is $0.28 \mu \mathrm{g} / \mathrm{kg}$ in 6-11-month-old infants and $0.22 \mu \mathrm{g} /$ $\mathrm{kg}$ in 2-year-old toddlers, which is around 5.5-7 times higher than the average daily intake in adults (http://toxnet.nlm.nih.gov/ cgi-bin/sis/search/a?dbs+hsdb:@term+@DOCNO+1528). It has been reported that the 8-hour acute absorbed daily dosage (ADD) calculated for aerial applicators handling the wettable powder in water soluble bags was $5300 \mu \mathrm{g} /$ day per kilogram $(\mathrm{kg})$ of body weight (http://www.cdpr.ca.gov/docs/whs/pdf/hs1527.pdf). We used both mouse and humanized mouse models show that daily exposure of propargite causes the decrease of cell number and increase of DNA damage of both mouse and human $\beta$-cells. It worth to note that that gating strategy in the primary screening $\left(60 \%\right.$ reduction in the survival rate of INS $^{+}$cells and $<20 \%$ loss of the INS $^{-}$cells) is very strict. In this study, we only focus on the environmental chemicals showing strong $\beta$-cell toxicity. The compounds showing weak acute $\beta$-cell toxicity might be missing. Further, we monitored the propargite's toxicity on different types of cells using hPSC-derived population. We suggested that propargite decreases cell number by affecting cell survival since most of the hPSC-derived population show relative high purity. We cannot fully exclude the possibility that propargite also affects hPSC differentiation.

Diabetes is a polygenic disease involving genetic and environmental factors. Although several epidemiology studies have reported gene-environment interactions in diabetes ${ }^{40,41}$, human population-based studies are also complicated by heterogeneous genetic backgrounds and dynamic environmental conditions, requiring very large sample sizes to identify interaction of genetic and environmental factors. Here, we report the first hESC/iPSCbased population study to determine gene-environment interactions on pancreatic $\beta$-cell survival and found that GSTT1-null cells exhibit increased sensitivity to propargite-induced pancreatic $\beta$-cell death, which was further validated using isogenic GSTT1 $-/-$ hESC-derived cells and an isogenic human pancreatic $\beta$-cell line. Although both GSTT1-null and GSTM1-null genotype are associated with increased risk of diabetes ${ }^{29-31}$ in GWAS, only GSTT1 ${ }^{-/}-\beta$-like cells show increased sensitivity to propargiteinduced cell death. One possible reason for this finding is that the expression levels of GSTT1 and GSTM1 might be different in human versus mouse islets. Notably, there was still a minimal signal in the compound-null GSTM1 knockout cells in the western-blot lanes. It could be due to the reduced stability of the indel-frameshift GSTM1 proteins, or the background of the GSTM1 antibody. Additional experiments will be required to more fully examine the differences between GSTT1-null and GSTM1-null cells. The hESC/iPSC-based system, in which both pancreatic $\beta$-cell derivation and environmental factors can be tightly controlled, provides a robust and relatively highthroughput platform to systematically examine the interactions of diabetes risk-associated genes and environmental factors.

The fact that the same risk factors and mechanism of propargite-mediated cell death apply to hPSC-derived midbrain DA neurons indicates the broader applicability of our findings and point to a shared susceptibility profile of $\beta$-cells and $\mathrm{mDA}$ neurons. Supporting epidemiological data on PD prevalence in populations exposed to well water with high propargite levels links the in vitro findings to actual patient data ${ }^{39}$. Our hPSCbased in vitro platform can be used to probe the impact of environmental factors for public health, and may facilitate the development of novel precision therapies for patients at risk of developing diabetes or PD.

\section{Methods}

Cell culture. hESCs were grown on Matrigel-coated plates with mTeSR1 medium (Stem Cell Technology). Cells were maintained at $37^{\circ} \mathrm{C}$ with $5 \% \mathrm{CO}_{2}$. MIN6 cells were a gift from Dr. Mingming Hao. Human $\beta$-cell line (EndoC- $\beta \mathrm{H} 1$ ) was purchased from Endocells. H1 hESCs were purchased from WiCell Institute. HUES8 hESCs were provided by Harvard University. HES3 hESCs were provided by Dr. Ed Stanley at Monash University, Australia.

hESC differentiation. The starting population of cells for the high-content chemical screen were derived from $\mathrm{H} 1 \mathrm{hESCs}$ following our previously reported stepwise differentiation protocol $(\beta \text {-cell differentiation protocol } 1)^{18}$. Hit compounds were validated using the cells derived using a strategy recently published by our lab ${ }^{20}$ ( $\beta$-cell differentiation protocol 2$)$. Cortical and mDA differentiation from hESC were done with similar protocols those published by our lab previously ${ }^{36,37}$.

High-content screen. The screening library ToxCast Phase I was obtained from the US Environmental Protection Agency, which contains approximately 2000 compounds dissolved at $20 \mathrm{mM}$ in DMSO. The $\mathrm{H} 1 \mathrm{hESC}$-derived population was dissociated with Accutase and re-plated onto laminin V-coated 384-well plates at 5000 cells per well. After $16 \mathrm{~h}$ incubation, cells were treated with individual compounds from the ToxCast library with four concentrations, including $20 \mathrm{nM}$, $200 \mathrm{nM}, 2 \mu \mathrm{M}$, and $20 \mu \mathrm{M}$, for each compound. After 4 days, the cells were fixed with $10 \%$ formalin and stained with an INS antibody and DAPI, followed by automatic imaging and analysis by ImageXpress ${ }^{\text {MICRO }}$ Automated High-Content Analysis System (Molecular Devices) to count the numbers of INS ${ }^{+}$and INS ${ }^{-}$cells The survival rate was calculated by dividing the numbers of $\mathrm{INS}^{+}$cells in compound treated conditions by the average number of $\mathrm{INS}^{+}$cells in DMSO-treated conditions. The compounds that induced more than $60 \%$ reduction of the survival rate of $\mathrm{INS}^{+}$cells and less than $20 \%$ of the $\mathrm{INS}^{-}$cells were chosen as primary hits. Hit compounds were then selected and validated in three additional independent experiments using the same protocol as the primary screening.

Generation of inhibitory curves. hESCs-derived INS ${ }^{+}$cells $^{42}, \mathrm{MSCs}^{43}$, neurons ${ }^{37}$, and hepatocytes ${ }^{44}$ were derived based on the reported protocols and re-plated on 96-well plates with Accutase digestion. Cardiomyocytes (CMs) were differentiated from H9-MYH6: mCherry reporter line, based on the reported protocol ${ }^{45}$. After overnight incubation, cells were treated with DMSO or different doses of hit compounds for 4 days. After fixation, the cells were stained with markers for each cell type. DAPI was used to stain cell nuclei. Plates were analyzed by ImageXpress ${ }^{\text {MICRO }}$ Automated High-Content Analysis System. 


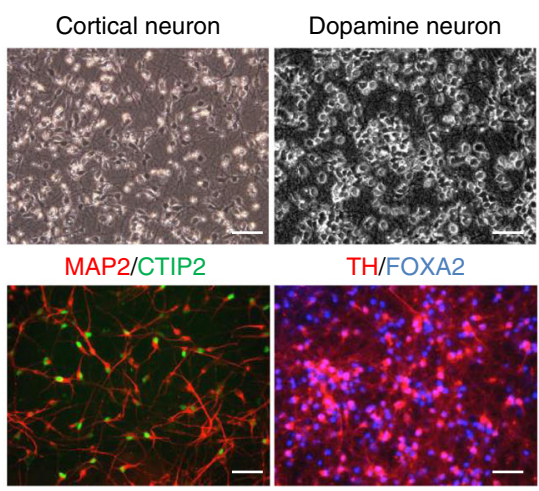

b

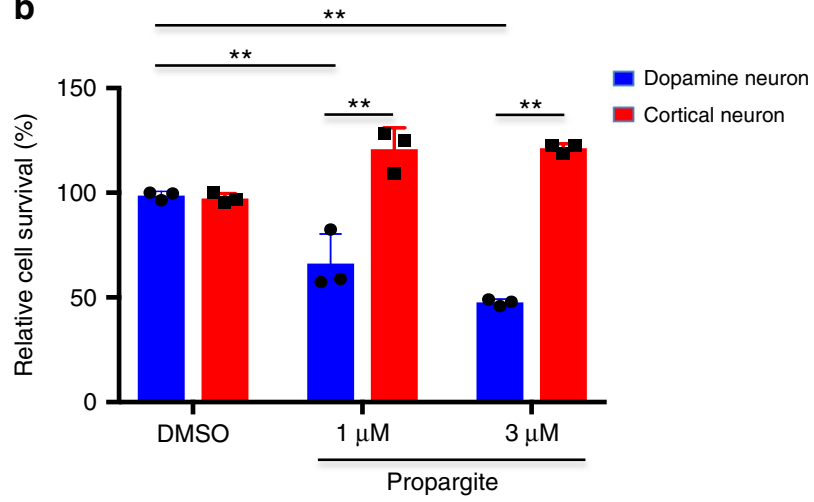

C
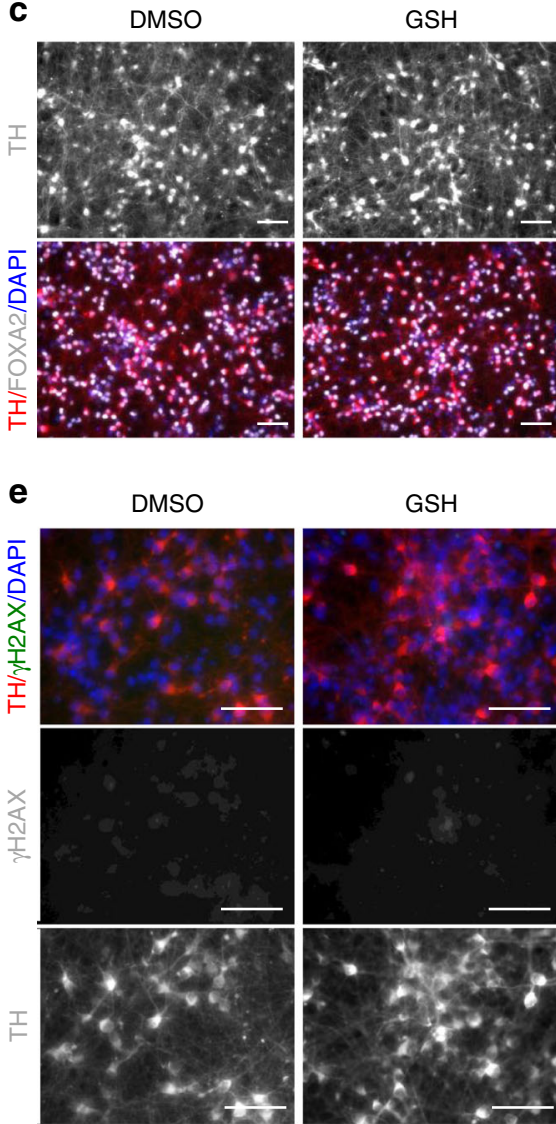

g

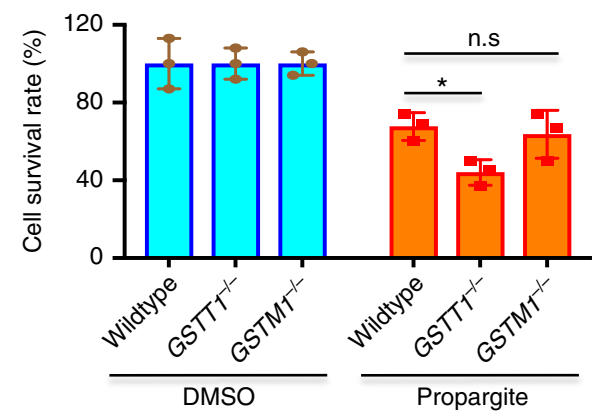

Creation of isogenic hESC lines. CRISPR sgRNA sequences were designed using the web resources available at http://www.genome-engineering.org/. The target sequences are listed in Supplementary Table 2. Each target sequence was cloned into the pX330-U6-Chimeric_BB-CBh-hSpCas9 vector (Addgene plasmid \#42230) to make the gene targeting constructs. To knockout the target genes, two sgRNAs were validated using the surveyor assay in $293 \mathrm{~T}$ cells, and we chose 1 sgRNAconstruct plasmid for further experiments. After validation, H1 or INS ${ }^{G F P / W}$ HES3

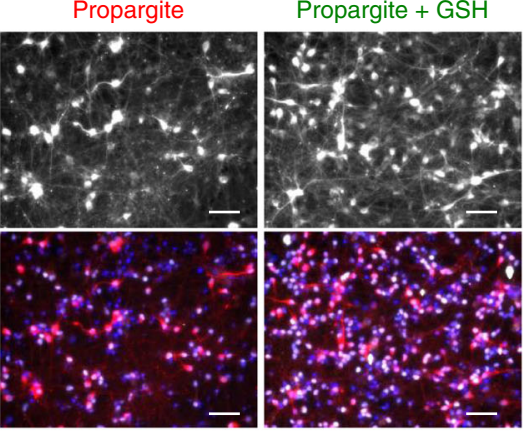

d
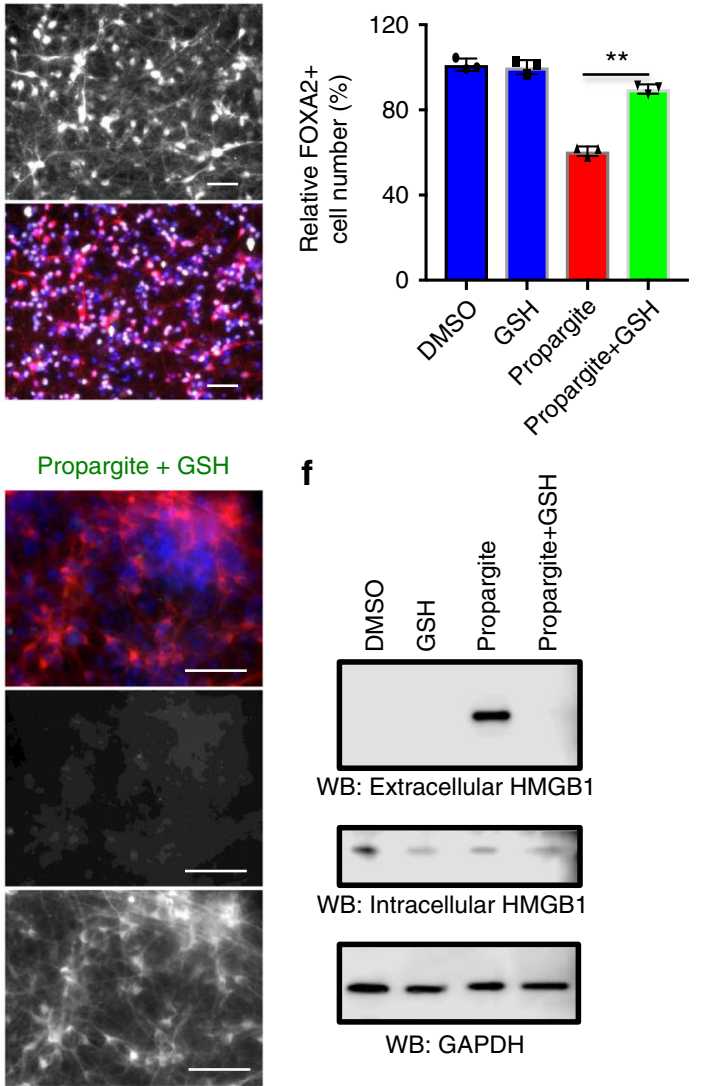

WB: Intracellular HMGB1

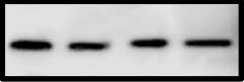

WB: GAPDH

h
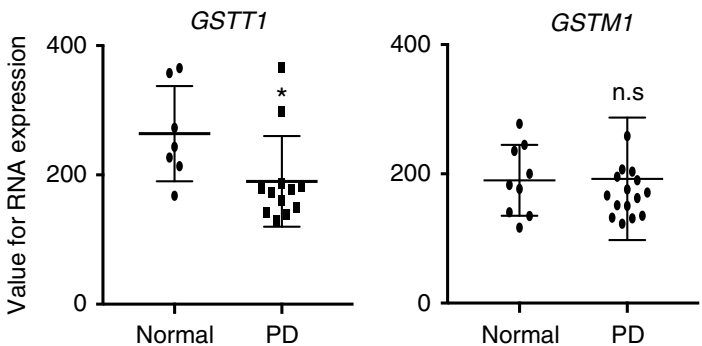

cells were dissociated using Accutase (STEM CELL) and electroporated $\left(8 \times 10^{5}\right.$ cells per sample) with $4 \mu \mathrm{g}$ sgRNA-construct plasmids using Human Stem Cell Nucleofector ${ }^{\mathrm{TM}}$ solution (Lonza) following manufacturer's instructions. The cells were then seeded into 2 wells of 24 -well plates. 4 days later, hESCs were dissociated into single cells by Accutase (STEM CELL) and re-plated at a low density (1-3 cells per well in 96-well plates). $10 \mu \mathrm{M}$ Y-27632 was added. 10 days later, individual colonies were picked, mechanically disaggregated and re-plated into two individual 
Fig. 4 Midbrain dopamine neurons are hypersensitive to propargite-induced cell toxicity. a Characterization of cortical neuron and mDA neuron derived from H9 hESCs. Upper panel represents bright field images of cortical- and mDA-neurons. Lower panel shows cortical neurons stained for MAP2 (red) and CTIP2 (green) while mDA neurons were stained for TH (red) and FOXA2 (blue). Scale bars, $50 \mu \mathrm{m}$. b Relative cell survival rate of cortical- and mDAneurons treated with DMSO or different doses of propargite. Relative cell survival was quantified by dividing propargite-treated cells to the DMSO control $(n=3)$. c, d Representative image $(\mathbf{c})$ and relative cell survival rate $(\mathbf{d})$ of $\mathrm{mDA}$ neurons treated with DMSO or propargite $(1 \mu \mathrm{M})$ in the presence or absence of GSH ( $2 \mathrm{mM}$ ). mDA cells were stained for TH (red) and FOXA2 (gray), and all cells were counterstained with DAPI (blue). Scale bars, $50 \mu \mathrm{m}$. Relative cell survival rate was analyzed by quantification of FOXA2+ (gray) cells $(n=3)$. e Representative image of mDA cells treated with DMSO, DMSO $+2 \mathrm{mM} \mathrm{GSH}, 1 \mu \mathrm{M}$ propargite, or $1 \mu \mathrm{M}$ propargite $+2 \mathrm{mM} \mathrm{GSH}$. White arrows indicate propargite-treated mDA cells (TH; red) co-stained with the DNA damage marker ( $r \mathrm{H} 2 \mathrm{AX}$; green), and all cells were counterstained with DAPI (blue). Scale bars, $50 \mu \mathrm{m}$. $\mathbf{f}$ Western blotting analysis of necrosis marker (extracellular HMGB1) in DMSO or propargite $(1 \mu \mathrm{M})$ treated mDA cells with/without GSH $(2 \mathrm{mM})$. Only propargite-treated mDA cell had high extracellular HMGB1 level $(n=3)$. $\mathbf{g}$ Relative cell survival rate, quantified by the expression of FOXA2+ cells $(n=3)$, of mDA cells derived from isogenic wild type, GSTT1 ${ }^{-/}$, and GSTM1 ${ }^{-/-} \mathrm{H} 1 \mathrm{hESC}$ s treated with DMSO and propargite ( $\left.3 \mu \mathrm{M}\right) . \mathbf{h}$ GSTT1, but not GSTM1 expression, in substantia nigra region of postmortem brains is significantly downregulated in Parkinson's disease patients compared to age-matched controls. Values for RNA expression used here are from a published gene expression data and selected values except absent its detection ${ }^{38}$. Values presented as mean \pm S.D. $p$-value was calculated by unpaired two-tailed Student's $t$-test were ${ }^{\star} p<0.05,{ }^{\star \star} p<0.01$. n.s. indicates a non-significant difference. Related to Supplementary Figs. 4 and 5
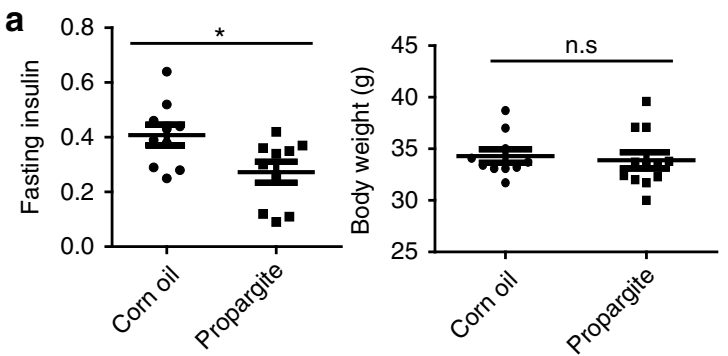

b
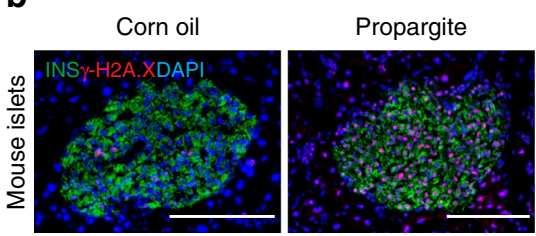

C

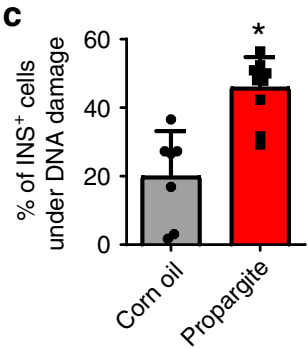

d
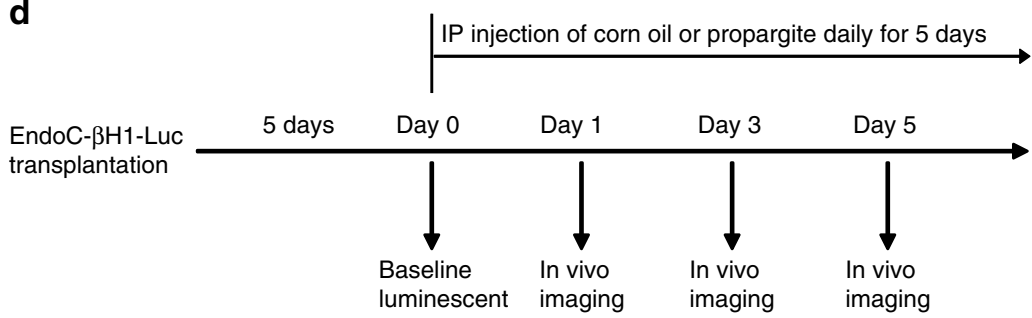

f

Day 3

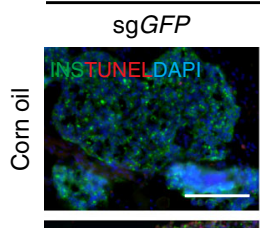

sgGSTT1-1

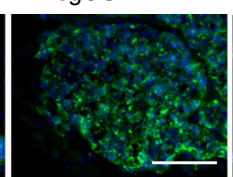

sgGSTT1-2
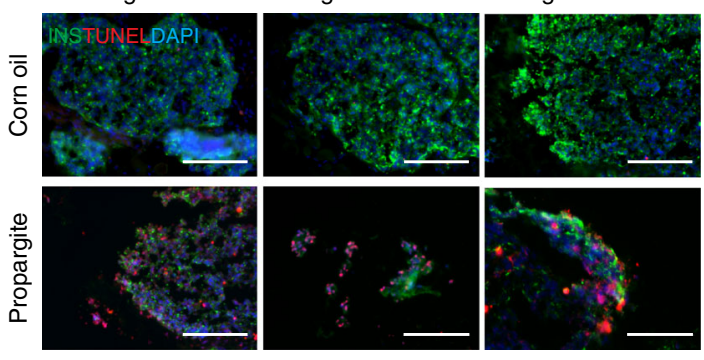

g

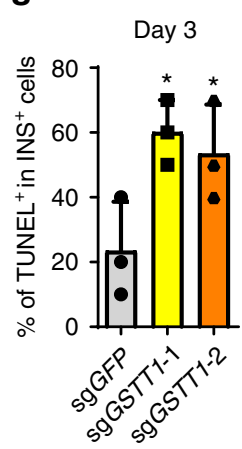

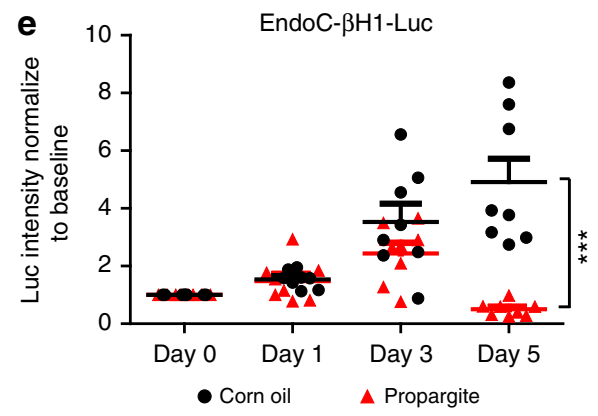

Fig. 5 Propargite induces $\beta$-cell toxicity in vivo. Fasting mouse insulin levels, and body weights in control (corn oil) or $12 \mathrm{mg} / \mathrm{kg}$ propargite-treated mice ( $n$ $=10$ mice). $p$ values calculated by one-way repeated measures ANOVA. b, c Representative images (b) and DNA damage rate (c) of mouse $\beta$-cells in mouse pancreas ( $n=7$ images for corn oil treated mice and $n=10$ images for Propargite-treated mice). DNA damage rate of mouse $\beta$-cells was calculated as the percentage of $\gamma-\mathrm{H} 2 \mathrm{~A} . \mathrm{X}^{+} / \mathrm{INS}^{+}$cells in INS ${ }^{+}$cells. Scale bars, $100 \mu \mathrm{m}$. $\mathbf{d}$ Scheme of the in vivo imaging analysis. Day 0 is the day the mice are first administrated with corn oil (vehicle) or propargite. e Fold-change of luciferase signals from EndoC- $\beta \mathrm{H} 1$-Luc cells transplanted mice administrated with corn oil (vehicle) or propargite during the 5 -day course $(n=8$ mice). $p$ values calculated by one-way repeated measures ANOVA. $\mathbf{f}, \mathbf{g}$ Representative images of TUNEL and INS staining (f) and Quantification of \%TUNEL+ cells ( $\mathbf{g}$ ) in EndoC- $\beta \mathrm{H} 1$-Luc cells carrying sgGSTT1 or sgGFP on day 3 ( $n=3$ images for each condition). $p$ values calculated by two-way repeated measures ANOVA with a Bonferroni test for multiple comparisons between wt and mutant cells. Related to Supplementary Fig. 6 
wells of 96-well plates. A portion of the cells was analyzed by DNA sequencing. For biallelic frameshift mutants, we chose both homozygous mutants or compound heterozygous mutants. Wild-type clonal lines from the corresponding targeting experiments were included as wild-type controls to account for potential nonspecific effects associated with the gene targeting process. During differentiation experiments, all lines were re-sequenced to confirm the genotypes. GSTM1 and GSTT1 knockout hESC lines were created based on H1 hESCs. The efficiencies for creating biallelic mutant lines were $68 \%$ for $\mathrm{GSTM1}^{-/-}$cells, $71 \%$ for $\mathrm{GSTT1}^{-/-}$ cells. (Supplementary Table 4).

Knockout of GSTT1 in a human $\boldsymbol{\beta}$-cell line. Two sgRNAs targeting two different loci on GSTT1 gene: $\operatorname{sgGSTT1-1}$ and sgGSTT1-2 and a sgRNA targeting GFP $(\operatorname{sgGFP})^{46}$ which has no specific targets on the human genome and was used as a control, were cloned into lentiCRISPRv2 vectors (Addgene plasmid \# 52961) ${ }^{47}$. EndoC- $\beta \mathrm{H} 1$ cells were infected with the lentivirus carrying Cas 9 and sgRNAs. After 2 days of selection with $1 \mu \mathrm{g} / \mathrm{ml}$ puromycin, western blots were used to validate the knockout efficiency.

RNA sequencing. The INS-GFP ${ }^{+}$cells were sorted and RNA from the sorted cells was extracted with Absolutely RNA Nanoprep kit (Agilent Technologies, 400753). The RNA quality was validated with a bioanalyzer (Agilent). The cDNA libraries were synthesized using the TruSeq RNA Sample Preparation kit (Illumina) and sequenced in single-read with the HiSeq2000/1000 sequencer (Illumina) at Weill Cornell Genomics Resources Core Facility. The reads were aligned to the human hg19 reference genome with Tophat $2^{48}$. Gene expression data were analyzed with Cufflinks $^{49}$. To generate heat maps displaying the differential gene expression patterns of different samples, the RPKM values were normalized per gene over all samples. The heat maps were then generated by Heatmap. 2 in the $\mathrm{R}$ plots package. David functional annotation tool ${ }^{50}$ was used for gene ontology analysis and Ingenuity Pathway Analysis tool was used for pathway analysis.

Immunocytochemistry. Cells were fixed with $10 \%(\mathrm{v} / \mathrm{v})$ formalin for $20 \mathrm{~min}$ at room temperature (RT) and blocked in a solution of $\mathrm{Mg}^{2+}$ - and $\mathrm{Ca}^{2+}$-free PBS containing $5 \%$ horse serum and $0.3 \%$ Triton- $\mathrm{X}$ for $1 \mathrm{~h}$ at room temperature and followed by incubation with primary antibody at $4{ }^{\circ} \mathrm{C}$ overnight. The following primary antibodies and dilutions have been used in this study: goat anti-SOX17 (1:500, R\&D system, AF1924), rabbit anti-FOXA2 (1:500, Upstate, 07-633), goat anti-PDX1 (1:500, R\&D system, AF2419), mouse anti-NKX6.1 (1:100; BCBC, Ab2024), guinea pig anti-INS (1:1000, Dako, A0564), guinea pig anti-GLUCAGON (1:500, Linco, 4031), mouse anti-Ki67 (1:100, Life technologies, 556003), mouse anti-AMYLASE (1:100, Santa Cruz, sc-46657), rabbit anti-Active Caspase-3 (1:500, BD Bioscience, 559565), mouse anti-Troponin T (1:500, Thermo Scientific, MA512960), mouse anti-Actin, Cardiac (1:300, Sigma, A9357), rabbit anti-TUJ1 (1:500, Covance, MRB-435P), Chicken anti-MAP2 (1:1000, Abcam, Ab5392), mouse anti$\mathrm{HuC} / \mathrm{D}$ (1:500, Invitrogen, A-21271), mouse anti-MAP2 (1:1500, Sigma, M1406), rabbit anti-TH (1:500, Pel freeze, P40101-0), rat-anti-CTIP2 (1:500, Abcam, ab18465), goat anti-FOXA2 (1:200, R\&D, 463783). Donkey anti-guinea pig, mouse, goat, rabbit or chicken secondary antibodies conjugated with Alexa-Fluor-488, Alexa-Fluor-594 or Alexa-Fluor-647 fluorophore (1:500, Life technologies) were used. Nuclei were counterstained by DAPI.

Real-time qPCR. Total RNA from FACS-sorted INS-GFP ${ }^{+}$cells was isolated using the Absolutely RNA Nanoprep kit (Agilent Technologies, 400753), quantified with a NanoDrop spectrophotometer (Thermo Scientific), and cDNA was synthesized with a high-capacity cDNA reverse transcription kit (Applied Biosystems, 4374966). Real-time qPCR was performed with a LightCycler 480 (Roche) instrument with LightCycler DNA master SYBR Green I reagents. Statistical significance was determined using a two-tailed Student's $t$-test $(p<0.005)$. Primer sequences are listed in Supplementary Table 1.

Western blotting analysis. To extract intracellular protein, cells were placed on ice, washed twice with ice-cold PBS and lysed immediately with RIPA buffer (Life Technologies, 89900) supplemented with a protease inhibitor cocktail (Life Technologies, 78440). Cell lysates were then sonicated and the soluble fraction was collected after centrifugation. Protein amount was quantified by the BCA protein assay (Life Technologies, 23227). To extract extracellular HMGB1, tissue culture media were collected and concentrated using Afyon SDS-PAGE sample preparation kit (advansta, K-02101-025). $20 \mu \mathrm{g}$ of total protein for each sample was mixed with loading buffer and incubated for $5 \mathrm{~min}$ at $95^{\circ} \mathrm{C}$ before being loaded into $\mathrm{NuPAGE}^{\circledast}$ Novex $^{\circledast}$ 4-12\% Tris-Acetate Protein Gels (Life Technologies, NP0321BOX) for electrophoresis. Separated proteins were transferred to a PVDF membrane (Millipore, IPSN07852) after electrophoresis. The membrane was blocked with $5 \%$ non-fat milk in TBST ( $50 \mathrm{mM}$ Tris- $\mathrm{HCl}$ at $\mathrm{pH} 8.0,150 \mathrm{mM} \mathrm{NaCl}$, $0.1 \%$ Tween 20) followed by overnight incubation with the primary antibody at $4^{\circ}$ C. The following antibodies were used with the dilution ratio noted: rabbit antiHMGB1 (1:1000, Cell Signaling Technology, \#6893), rabbit anti- $\gamma$-H2A.X (1:1000, Cell Signaling Technology, \#9718), rabbit anti-LC3B (1:1000, Cell Signaling Technology, \#3868), mouse anti-GSTT1 (1:1000, GeneTex, GTX109250), rabbit anti-GSTM1 (1:1000, R\&D system, MAB6894), mouse anti-GAPDH (1:50000,
Abcam, ab8245). A peroxidase conjugated horse anti-mouse IgG secondary antibody (1:20000, Vector Laboratories, PI-2000) or peroxidase conjugated goat antiRabbit IgG secondary antibody (1:20000, Vector Laboratories, PI-1000) was used for western blot. ECL signals were developed and detected using the SuperSignal ${ }^{\mathrm{m}}$ West Femto Maximum Sensitivity Substrate (Life Technologies, 34094) and a CDiGit Chemiluminescent Western Blot Scanner (LI-COR). Uncropped scans of all the blots were shown in Supplementary Fig. 7 in the Supplementary Information.

Flow cytometry. Cells were harvested with Accutase, intracellular flow cytometry was performed with Cytofix/Cytoperm ${ }^{\text {mix }}$ Fixation/Permeabilization Kit (BD, 554714) according to the user menu. The following primary antibodies and dilutions have been used in this study: C-peptide (1:1000, Millipore, 05-1109), mouse anti-human CD73 (1:1000, BD Pharmingen, 560847) and mouse anti-human CD29 (1:500, eBioscience, 12-0299-41). Cells were stained with primary antibody for $1 \mathrm{~h}$, followed with donkey anti-mouse Alexa-efluor 488 secondary antibody (1:500, Life technologies). After washing twice, cells were resuspended in PBS plus $300 \mathrm{nM}$ DAPI (Invitrogen, D21490) and followed by analysis with FACSVantage SE (Becton Dickinson).

Annexin V cellular apoptosis analysis. Cells were dissociated by Accutase (Stem Cells) and washed with cold DPBS and then detected with FITC Annexin V Apoptosis Detection Kit I (BD Bioscience, 556547), and analyzed within $1 \mathrm{~h}$ by FACSVantage SE (Becton Dickinson).

Intracellular ROS and total GSH measurement. Total intracellular ROS were detected using DCFDA-Cellular Reactive Oxygen Species Detection Assay Kit (Abcam, ab113851). Total GSH was measured using GSH-Glo ${ }^{\text {max }}$ Glutathione Assay (Promega, V6911).

Genotype analysis of GSTM1 and GSTT1. We used a multiplex PCR to detect GSTM1 and GSTT1 as well as an internal control ( $\beta$-globin) in a one-tube reaction (modified from a published method ${ }^{51}$ ) to analyze the polymorphism of GSTM1 and GSTM1. Genomic DNA of 3 hESCs and 7 hiPSCs were extracted using the DNeasy Blood \& Tissue Kit (QIAGEN, 69506). The 3 genes were amplified from the individual genomic DNAs using primers and a PCR program listed in Supplementary Table 5 . The genomic DNA were amplified using the following program: (1) $94{ }^{\circ} \mathrm{C}, 4 \mathrm{~min}$; (2) 34 cycles of $1 \mathrm{~min}$ at 94,60 , and $72{ }^{\circ} \mathrm{C}$; (3) $72{ }^{\circ} \mathrm{C}$ for 5 min. The PCR products were electrophoresed on $2 \%$ agarose gels stained with ethidium bromide.

Measurement propargite's effect on mice. All animal work has been approved by IACUC committee of Weill Cornell Medical College. CD-1 adult male mice were treated with different doses of propargite or vehicle (corn oil) through intraperitoneal injection for 5 days. Fasting blood glucose level were monitored every day using Abbott FreeStyle Lite blood glucose monitoring system. Then, CD1 adult male mice were treated with $12 \mathrm{mg} / \mathrm{kg}$ propargite or vehicle (corn oil) through intraperitoneal injection for 5 days. Fasting blood was collected via tail nicking following $14-16 \mathrm{~h}$ of fasting with ad libitum access to drinking water. Serum mouse insulin levels were assessed by ELISA (80-INSMR-CH01, Alpco). Mice were then killed. The pancreases were embedded in OCT. The tissue was then sectioned at $5 \mu \mathrm{m}$ for immunohistochemistry staining analysis of DNA damage marker $\gamma$-H2A.X and $\beta$-cell marker INS.

Creation of humanized mice and in vivo imaging. LentiLuc-blast plasmid was constructed based on the LentiCas9-blast vector (Addgene, 52926). The luciferase gene was driven by a constitutively active EFS promoter. EndoC- $\beta \mathrm{H} 1$ cells were infected with the lentivirus followed by 4 days selection with $20 \mu \mathrm{g} / \mathrm{ml}$ blasticidin to create EndoC- $\beta$ H1-Luc cells. Adult 6-8 week old female NSG immunodeficient mice (Jackson Laboratory) were transplanted with $5 \times 10^{5}$ EndoC- $\beta$ H1-Luc cells to create a humanized mouse model. Baseline luminescent levels were obtained 5 days after transplantation. $12 \mathrm{mg} / \mathrm{kg}$ propargite or vehicle were then administrated for 5 days via intraperitoneal injection (the starting day referred to as day 0 ). In vivo imaging was performed on day 1,3 , and 5 with an Xtreme Optical and X-ray small animal imaging system. During the imaging, isoflurane was used for anesthesia. 2 $\mathrm{mg} / 150 \mu \mathrm{l} / 25 \mathrm{~g}$ body weight luciferin potassium salt (Regis, 360223) was applied to each mouse. To generate EndoC- $\beta \mathrm{H} 1$-Luc cells carrying sgGSTT1 or sgGFP,

EndoC- $\beta \mathrm{H} 1-\mathrm{Luc}$ cells were infected with the lentivirus carrying Cas 9 and sgRNAs ( $\mathrm{ggGSTT1}$ or sgGFP), and purified with 2 days selection using $1 \mu \mathrm{g} / \mathrm{ml}$ puromycin. Adult 6-8-week-old female NSG-immunodeficient mice (Jackson Laboratory) were transplanted with $5 \times 10^{5}$ EndoC- $\beta$ H1-Luc cells carrying sgGSTT1 or sgGFP (control). $12 \mathrm{mg} / \mathrm{kg}$ propargite or vehicle were administrated for 3 days via intraperitoneal injection, mice were then sacrificed at day 3 . The xenografts were embedded in OCT. The tissue was then sectioned at $5 \mu \mathrm{m}$ to detect cell death with TUNEL assays (In Situ Cell Death Detection Kit, TMR red, Sigma, 12156792910) and for immunohistochemistry staining analysis of $\beta$-cell marker INS to measure cell death rate in EndoC- $\beta$ H1-Luc cells carrying sgGSTT1 or sgGFP. 
Statistical analysis. $n=3$ independent biological replicates if not otherwise specifically indicated. n.s. indicates non-significant difference. $p$ values were calculated by unpaired two-tailed Student's $t$-test if not otherwise specifically indicated. ${ }^{*} p<0.05,{ }^{* *} p<0.01$, and ${ }^{* *} p<0.001$.

\section{Data availability}

The data that support the findings of this study are available from the corresponding author upon request. RNA-Seq data is available in GEO database (accession number: GSE83699).

Received: 3 November 2017 Accepted: 23 October 2018 Published online: 16 November 2018

\section{References}

1. Barrett, J. C. et al. Genome-wide association study and meta-analysis find that over 40 loci affect risk of type 1 diabetes. Nat. Genet. 41, 703-707 (2009).

2. Bradfield, J. P. et al. A genome-wide meta-analysis of six type 1 diabetes cohorts identifies multiple associated loci. PLoS Genet. 7, e1002293 (2011).

3. Replication, D. I. G. et al. Genome-wide trans-ancestry meta-analysis provides insight into the genetic architecture of type 2 diabetes susceptibility. Nat. Genet. 46, 234-244 (2014)

4. Steinthorsdottir, V. et al. Identification of low-frequency and rare sequence variants associated with elevated or reduced risk of type 2 diabetes. Nat. Genet. 46, 294-298 (2014).

5. Morris, A. P. et al. Large-scale association analysis provides insights into the genetic architecture and pathophysiology of type 2 diabetes. Nat. Genet. 44, 981-990 (2012).

6. Nica, A. C. et al. Cell-type, allelic, and genetic signatures in the human pancreatic beta cell transcriptome. Genome Res. 23, 1554-1562 (2013).

7. Knip, M. \& Akerblom, H. K. Environmental factors in the pathogenesis of type 1 diabetes mellitus. Exp. Clin. Endocrinol. Diabetes 107 Suppl 3, S93-S100 (1999).

8. Prasad, R. B. \& Groop, L. Genetics of type 2 diabetes-pitfalls and possibilities. Genes 6, 87-123 (2015).

9. Neel, B. A. \& Sargis, R. M. The paradox of progress: environmental disruption of metabolism and the diabetes epidemic. Diabetes 60, 1838-1848 (2011).

10. Longnecker, M. P., Klebanoff, M. A., Brock, J. W., Zhou, H. \& Collaborative Perinatal, P. Polychlorinated biphenyl serum levels in pregnant subjects with diabetes. Diabetes Care 24, 1099-1101 (2001).

11. Langer, P. et al. High prevalence of anti-glutamic acid decarboxylase (antiGAD) antibodies in employees at a polychlorinated biphenyl production factory. Arch. Environ. Health 57, 412-415 (2002).

12. Lang, I. A. et al. Association of urinary bisphenol A concentration with medical disorders and laboratory abnormalities in adults. JAMA 300, 1303-1310 (2008).

13. Bodin, J. et al. Long-term bisphenol A exposure accelerates insulitis development in diabetes-prone NOD mice. Immunopharmacol. Immunotoxicol. 35, 349-358 (2013).

14. Bodin, J. et al. Transmaternal bisphenol A exposure accelerates diabetes type 1 development in NOD mice. Toxicol. Sci. 137, 311-323 (2014).

15. Soriano, S. et al. Rapid insulinotropic action of low doses of bisphenol-A on mouse and human islets of Langerhans: role of estrogen receptor beta. PLoS ONE 7, e31109 (2012).

16. $\mathrm{Lu}, \mathrm{T}$. H. et al. Arsenic induces pancreatic beta-cell apoptosis via the oxidative stress-regulated mitochondria-dependent and endoplasmic reticulum stresstriggered signaling pathways. Toxicol. Lett. 201, 15-26 (2011).

17. Ryan, S. D. et al. Isogenic human iPSC Parkinson's model shows nitrosative stress-induced dysfunction in MEF2-PGC1alpha transcription. Cell 155, 1351-1364 (2013).

18. Chen, S. et al. A small molecule that directs differentiation of human ESCs into the pancreatic lineage. Nat. Chem. Biol. 5, 258-265 (2009).

19. Karam, J. H. et al. Insulinopenic diabetes after rodenticide (Vacor) ingestion: a unique model of acquired diabetes in man. Diabetes 29, 971-978 (1980).

20. Zeng, H. et al. An isogenic human ESC platform for functional evaluation of genome-wide-association-study-identified diabetes genes and drug discovery. Cell Stem Cell 19, 326-340 (2016).

21. Micallef, S. J. et al. INS(GFP/w) human embryonic stem cells facilitate isolation of in vitro derived insulin-producing cells. Diabetologia 55, 694-706 (2012).

22. Sharma, A., Singh, K. \& Almasan, A. Histone H2AX phosphorylation: a marker for DNA damage. Methods Mol. Biol. 920, 613-626 (2012).

23. Surova, O. \& Zhivotovsky, B. Various modes of cell death induced by DNA damage. Oncogene 32, 3789-3797 (2013).

24. Kabeya, Y. et al. LC3, a mammalian homologue of yeast Apg8p, is localized in autophagosome membranes after processing. EMBO J. 19, 5720-5728 (2000).
25. Scaffidi, P., Misteli, T. \& Bianchi, M. E. Release of chromatin protein HMGB1 by necrotic cells triggers inflammation. Nature 418, 191-195 (2002).

26. Yang, $H$. et al. Programmed necrosis induced by asbestos in human mesothelial cells causes high-mobility group box 1 protein release and resultant inflammation. Proc. Natl Acad. Sci. USA 107, 12611-12616 (2010).

27. Townsend, D. M. \& Tew, K. D. The role of glutathione-S-transferase in anticancer drug resistance. Oncogene 22, 7369-7375 (2003).

28. Franca, R. et al. Glutathione S-transferase homozygous deletions and relapse in childhood acute lymphoblastic leukemia: a novel study design in a large Italian AIEOP cohort. Pharmacogenomics 13, 1905-1916 (2012).

29. Zhang, J., Liu, H., Yan, H., Huang, G. \& Wang, B. Null genotypes of GSTM1 and GSTT1 contribute to increased risk of diabetes mellitus: a meta-analysis. Gene 518, 405-411 (2013).

30. Saadat, M. Null genotypes of glutathione S-transferase M1 (GSTM1) and T1 (GSTT1) polymorphisms increased susceptibility to type 2 diabetes mellitus, a meta-analysis. Gene 532, 160-162 (2013).

31. Pinheiro, D. S. et al. Evaluation of glutathione S-transferase GSTM1 and GSTT1 deletion polymorphisms on type-2 diabetes mellitus risk. PLoS ONE $\mathbf{8}$, e76262 (2013)

32. Ravassard, P. et al. A genetically engineered human pancreatic beta cell line exhibiting glucose-inducible insulin secretion. J. Clin. Invest. 121, 3589-3597 (2011).

33. Gatto, N. M., Cockburn, M., Bronstein, J., Manthripragada, A. D. \& Ritz, B. Well-water consumption and Parkinson's disease in rural California. Environ. Health Perspect. 117, 1912-1918 (2009).

34. Braak, H., Ghebremedhin, E., Rub, U., Bratzke, H. \& Del Tredici, K. Stages in the development of Parkinson's disease-related pathology. Cell Tissue Res. 318, 121-134 (2004).

35. Davie, C. A. A review of Parkinson's disease. Br. Med. Bull. 86, 109-127 (2008).

36. Kriks, S. et al. Dopamine neurons derived from human ES cells efficiently engraft in animal models of Parkinson's disease. Nature 480, 547-551 (2011).

37. Chambers, S. M. et al. Highly efficient neural conversion of human ES and iPS cells by dual inhibition of SMAD signaling. Nat. Biotechnol. 27, 275-280 (2009).

38. Lesnick, T. G. et al. A genomic pathway approach to a complex disease: axon guidance and Parkinson disease. PLoS Genet. 3, e98 (2007).

39. Bovee, T. F., Helsdingen, R. J., Hamers, A. R., Brouwer, B. A. \& Nielen, M. W. Recombinant cell bioassays for the detection of (gluco)corticosteroids and endocrine-disrupting potencies of several environmental PCB contaminants. Anal. Bioanal. Chem. 401, 873-882 (2011).

40. Langenberg, C. et al. Gene-lifestyle interaction and type 2 diabetes: the EPIC interact case-cohort study. PLoS Med. 11, e1001647 (2014).

41. Cornelis, M. C. \& Hu, F. B. Gene-environment interactions in the development of type 2 diabetes: recent progress and continuing challenges. Annu. Rev. Nutr. 32, 245-259 (2012).

42. Rezania, A. et al. Reversal of diabetes with insulin-producing cells derived in vitro from human pluripotent stem cells. Nat. Biotechnol. 32, 1121-1133 (2014).

43. Ahfeldt, T. et al. Programming human pluripotent stem cells into white and brown adipocytes. Nat. Cell Biol. 14, 209-219 (2012).

44. Kajiwara, M. et al. Donor-dependent variations in hepatic differentiation from human-induced pluripotent stem cells. Proc. Natl Acad. Sci. USA 109, 12538-12543 (2012).

45. Birket, M. J. et al. Expansion and patterning of cardiovascular progenitors derived from human pluripotent stem cells. Nat. Biotechnol. 33, 970-979 (2015).

46. Shalem, O. et al. Genome-scale CRISPR-Cas9 knockout screening in human cells. Science 343, 84-87 (2014).

47. Sanjana, N. E., Shalem, O. \& Zhang, F. Improved vectors and genome-wide libraries for CRISPR screening. Nat. Methods 11, 783-784 (2014)

48. Kim, D. et al. TopHat2: accurate alignment of transcriptomes in the presence of insertions, deletions and gene fusions. Genome Biol. 14, R36 (2013).

49. Trapnell, C. et al. Transcript assembly and quantification by RNA-Seq reveals unannotated transcripts and isoform switching during cell differentiation. Nat. Biotechnol. 28, 511-515 (2010).

50. Huang da, W., Sherman, B. T. \& Lempicki, R. A. Systematic and integrative analysis of large gene lists using DAVID bioinformatics resources. Nat. Protoc. 4, 44-57 (2009).

51. Dirksen, U. et al. Glutathione S transferase theta 1 gene (GSTT1) null genotype is associated with an increased risk for acquired aplastic anemia in children. Pediatr. Res. 55, 466-471 (2004).

\section{Acknowledgements}

S.C. is funded by The New York Stem Cell Foundation (R-103), NIH (DP2 DK09809301, 1 DP3DK111907-01, 1 R01 DK116075-01A1), NCI (U01 CA224326-01), American Diabetes Association (1-17-IBS-019), and Tri-institutional Starr Stem Cell Grant (2014030). S.C. is New York Stem Cell Foundation-Robertson Investigator. Ti.Z. is funded by a 
Family Friendly Postdoctoral (FFPI) program at Weill Cornell. T.W.K is funded by The New York Stem Cell Foundation (NYSCF-D-F50). T.W.K. is a New York Stem Cell Foundation-Druckenmiller Fellow. C.R. is funded by a NIDDK fellowship. This study was also supported by a Shared Facility contract to T.E. and S.C. from the New York State Department of Health (NYSTEM C029156) and by a contract from the New York State Department of Health (NYSTEM C028503) and by R01AG054720 from the National Institute of Aging to L.S. with additional core grant support from P30CA008748. We are also very grateful for technical support and advice provided by Harold S. Ralph in the Cell Screening Core Facility, Jason McCormick in the Flow Cytometry Facility and Lee Cohen-Gould in the Election Microscopy Facility at Weill Cornell Medical College, NY.

\section{Author contributions}

S.C. and Ti.Z. designed the project; Ti.Z. and T.W.K. performed most key experiments; C.C., L.T., S.A., S.M., Z.G., H.Z., M.G., M.C., C.R., R.K., E.A., Z.B., and H.W. performed additional necessary experiments; Tu.Z. and J.Z.X. performed the bioinformatics analysis; Ti.Z., T.W.K., and S.C. analyzed data; Ti.Z., T.W.K., C.R. T.E., L.S., and S.C. wrote the manuscript.

\section{Additional information}

Supplementary Information accompanies this paper at https://doi.org/10.1038/s41467018-07201-1.

Competing interests: The authors declare no competing interests.
Reprints and permission information is available online at http://npg.nature.com/ reprintsandpermissions/

Publisher's note: Springer Nature remains neutral with regard to jurisdictional claims in published maps and institutional affiliations.

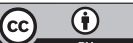

Open Access This article is licensed under a Creative Commons Attribution 4.0 International License, which permits use, sharing, adaptation, distribution and reproduction in any medium or format, as long as you give appropriate credit to the original author(s) and the source, provide a link to the Creative Commons license, and indicate if changes were made. The images or other third party material in this article are included in the article's Creative Commons license, unless indicated otherwise in a credit line to the material. If material is not included in the article's Creative Commons license and your intended use is not permitted by statutory regulation or exceeds the permitted use, you will need to obtain permission directly from the copyright holder. To view a copy of this license, visit http://creativecommons.org/ licenses/by/4.0/.

(c) The Author(s) 2018 